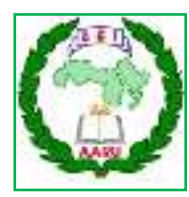

مجلة اتحاد الجامعات العربية للعلوم الزراعية، جامعة عين شمس، القاهرة، مصر مجلد(29)، عدد(1)، 59 - 82، 2021

Website: http://ajs.journals.ekb.eg

DOI: 10.21608/ajs.2020.40679.1244

أثر السياسات السعرية علي أهم المتغيرات الاقتصادية لمحصول البطاطس في مصر

[4]

\author{
حسين حسن علي ادم" \\ قسم الاقتصاد الزراعي - كلية الزراعة والموارد الطبيعية -جامعة أسوان - أسوان - مصر
}

*Corresponding author: hhussienadam@yahoo.com

Received 26 August, 2020

Accepted 21 Febraury, 2021

8097.89 جنيهاً، وقد بلغ متوسط الاستهلاك، وكمية

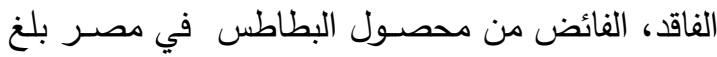

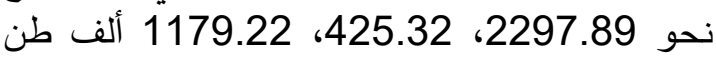

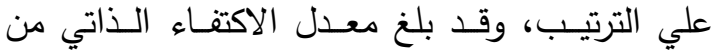

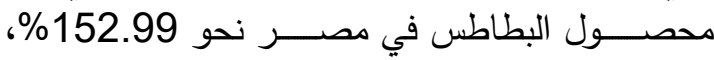

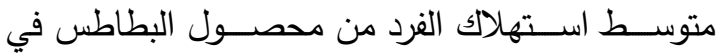

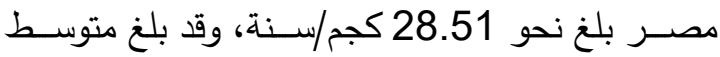

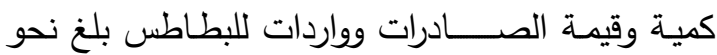
106.44، 18.02 ألف طن، 145.63، 145. مليون دولار للطن علي الترتيب وقد بلغ الميزان التجاري للبطاطس نحو 7469 مليون دولار خلال الفترة السابق التئل

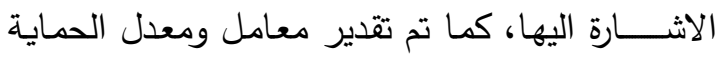

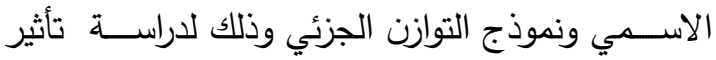

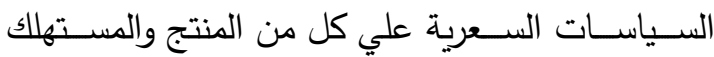

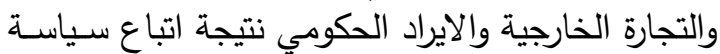

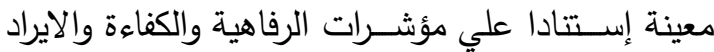

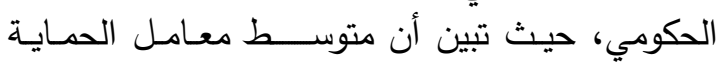

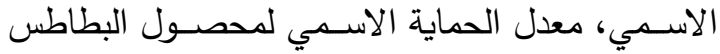

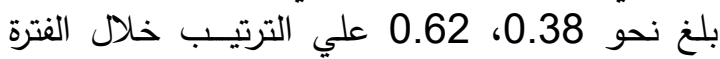

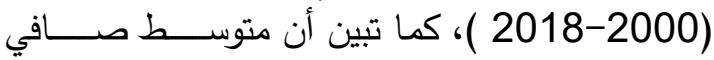

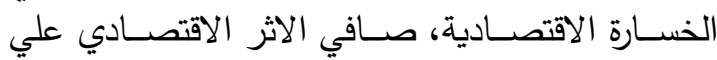

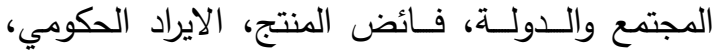

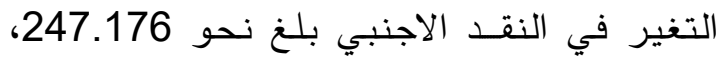
426.96، 904.352، ألف جنيه علي الترتيب خلال الفترة (2000-2018).

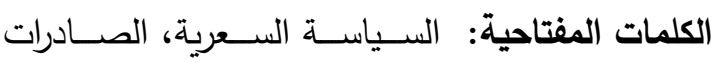
الزراعية المصرية، البطاطس، نموذج التوازن الجزئي

\section{الموج.}

تحتل البطاطس مكانة متميزة في المقتصـــ الزراعي

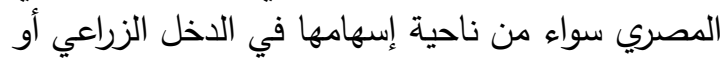

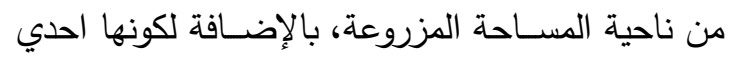

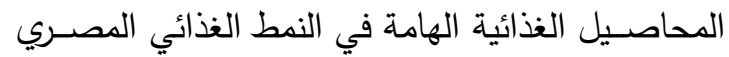

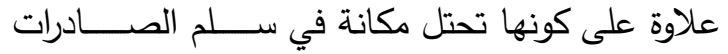

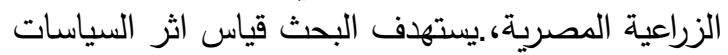

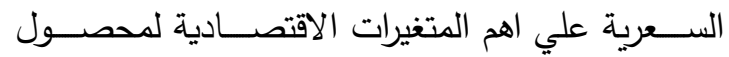

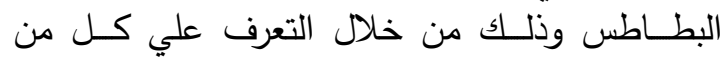

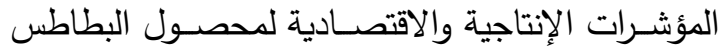

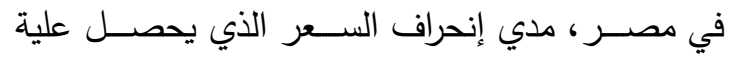

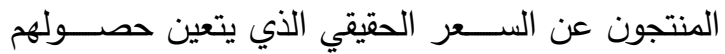

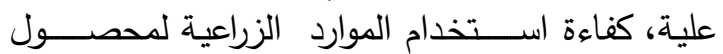

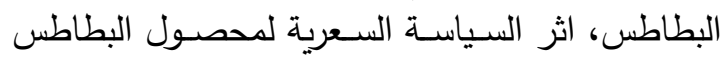

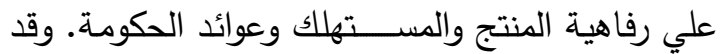

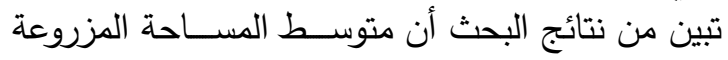

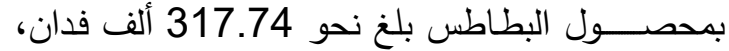
الانتاجية الفدانية، الانتاج الكلي بلغ نحو 10.82 بلن طن،

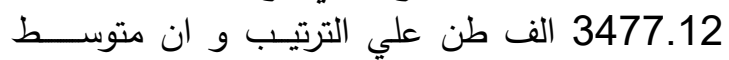

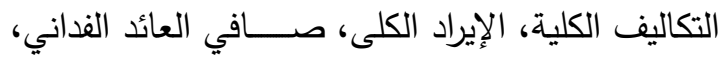
الســـر المزرعي بلغ نحو 14148.

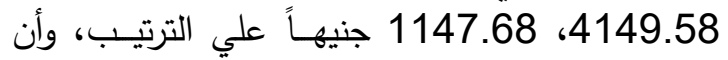

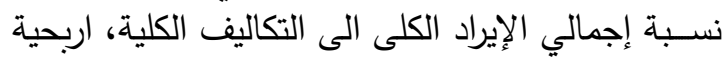

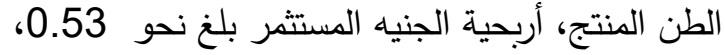

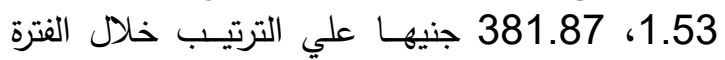

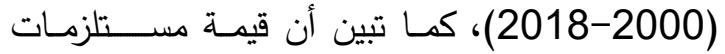

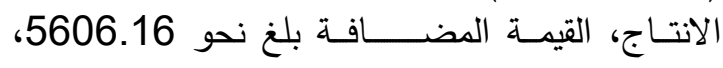


علي قدرته التنافسية وتدعيمها لزيادة الصادرات منه

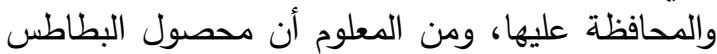
تزداد أهميته التصديرية في ظل اتفاقية الثران النراكة مع الدول

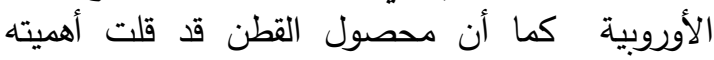

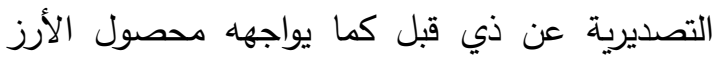

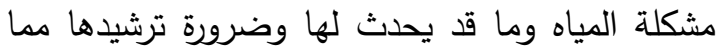

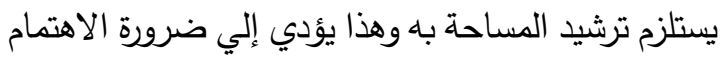
بالمحاصيل التصديرية الاخري مثل البطاطس والنباتات الطبية والعطرية، كما يعد البطاطس من الإلئل المحاصيل

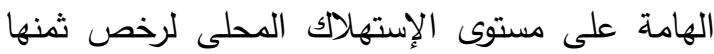

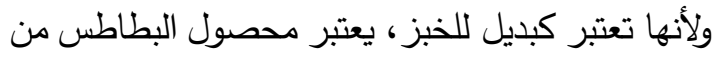

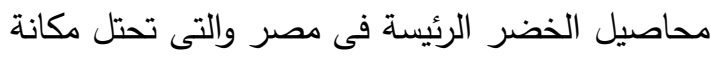

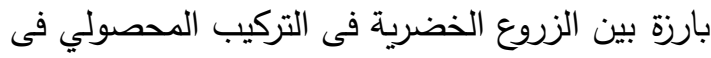

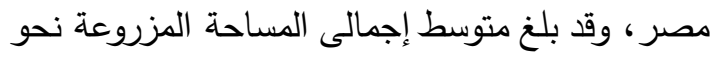

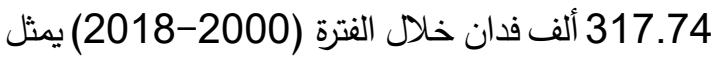

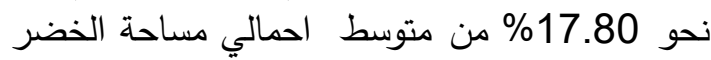

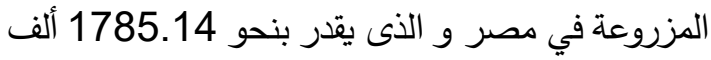

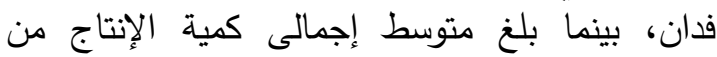

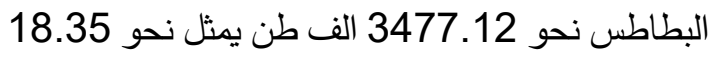
\% من المتوسط السنوي لإجمالي إنتاج الخضر المصنية

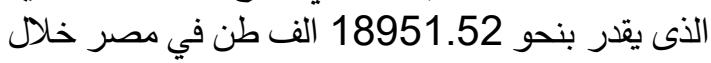
الفترة السابق الاشارة اليه، كما يعتبر محصول البطاطس

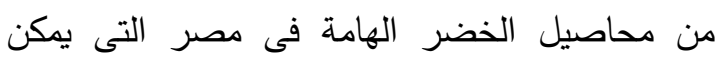
الإعتماد عليها فى زيادة حصيلة الصادرات فقد تزايدت

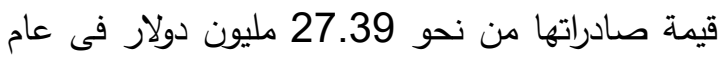

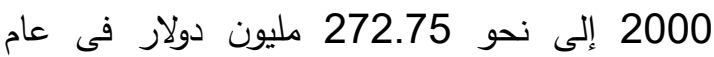
2018. وتعد السياسة السعرية أحد الأدوات الهامة فلعاد

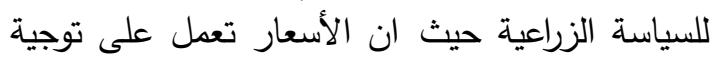

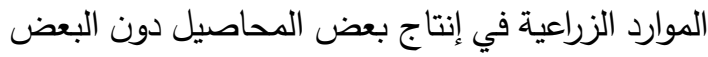
الآخر، وتعمل على توزيع الإنتاج على الإنى المستهلكين

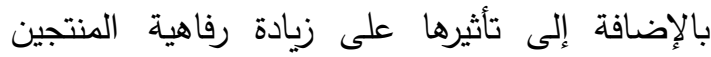
والمستهلكين واخيرا تاثيرها على عوائد الدولة.

\section{2 مشكلة البحث}

بالرغم من أن الدولة فى السنوات الأخيرة قد واجهت

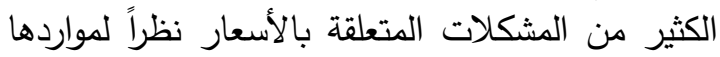
المحدودة والتى أدت إلى عدم معرفة أثر التغيرات العالمية التئية

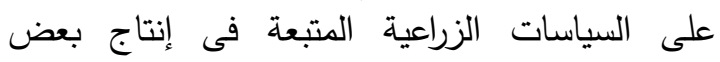

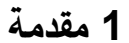

تحتل البطاطس مكانة متميزة في المقتصد الزراعي

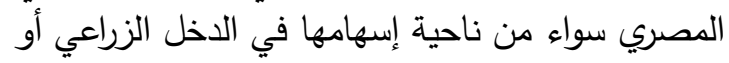

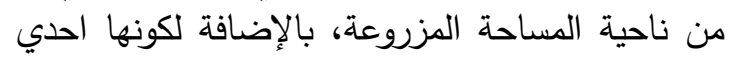

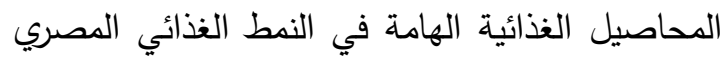

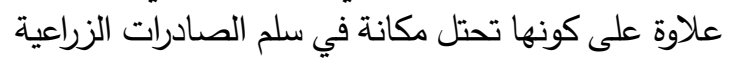

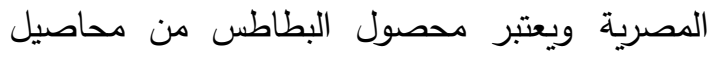
الخضر الإستراتيجية في مصر باعتباره من المحاصيل

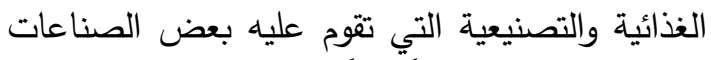

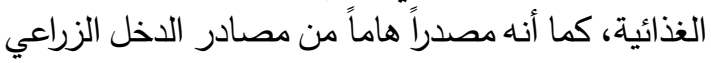

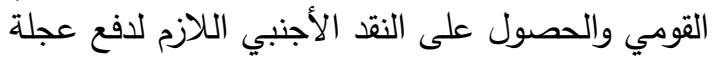

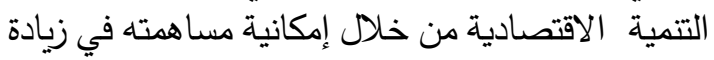

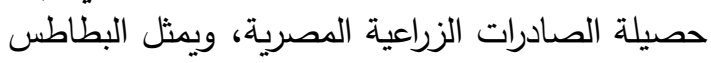

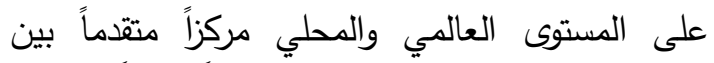

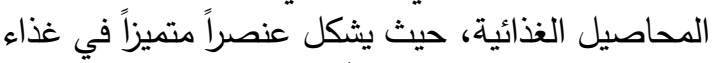

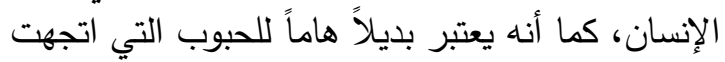

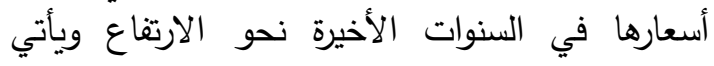
البطاطس في مقدمة السلع التي يمكن الاعتماد فئ عليها جزئياً في حل مشكلة الغذاء حيث يتميز لفي لالوفرة النسبية

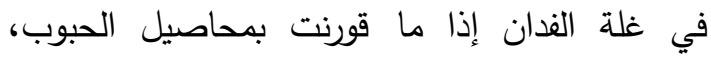

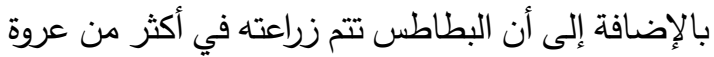

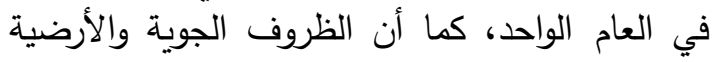

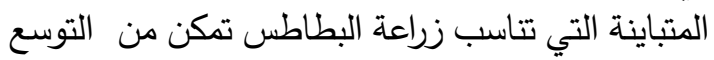

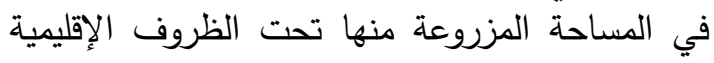

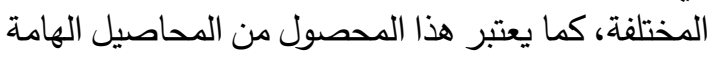

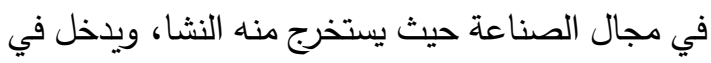
صناعة الجلوكوز، كما يستخدم في صناعة الحناعة الخمور

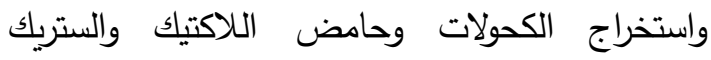

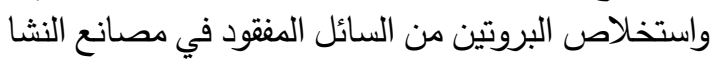

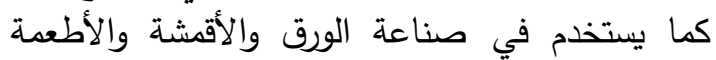

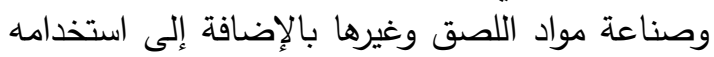

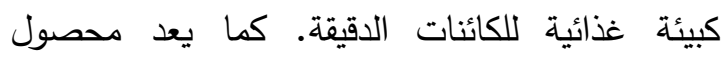
البطاطس من أهم محاصيل الخضر في مصر سواء للاء

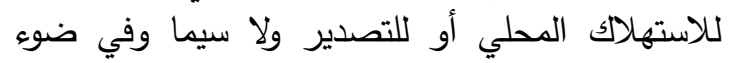

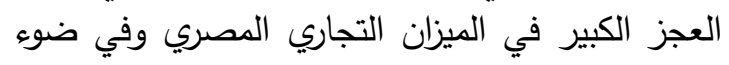
التقلبات العالمية المتعاقبة والمالية والاقتصادية التئية العالمية وفية

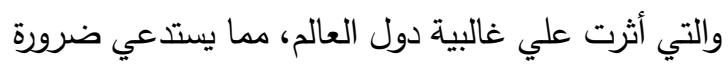

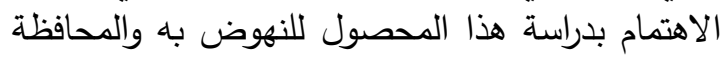


والإحصائية لمعالجة البيانات ومدى توافقها مع المنطق

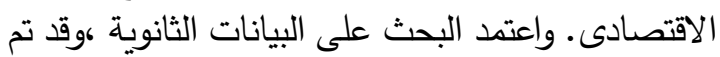
الحصول علي البيانات الثانوية من العديد من الوزارات التئي

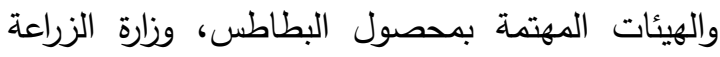

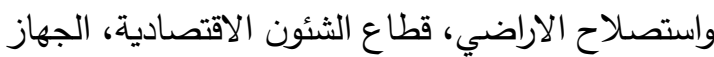

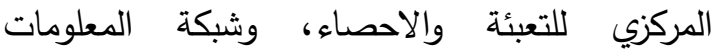

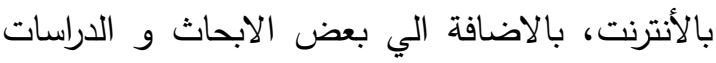

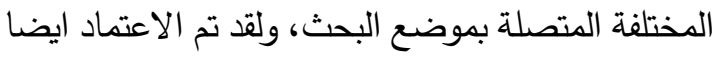

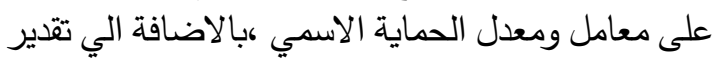

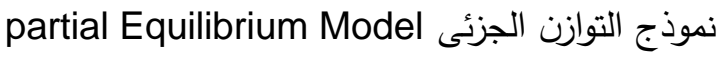

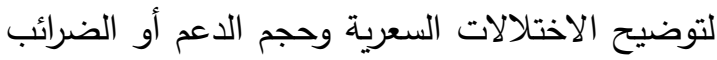

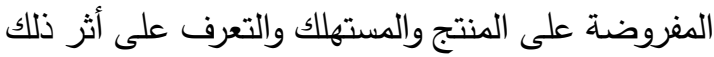

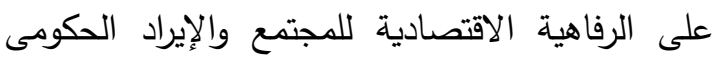

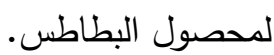

\section{4 مناقشة النتائج}

اولا: المؤشرات الإنتاجية والاقتصادية والاستهلاكية

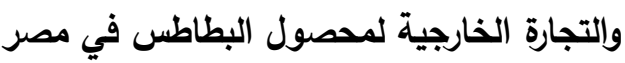
يتتاول هذا الجزء كل من المؤشرات الاتتاجية والاقتصادية، مؤشرات الاستهلاك، مؤشرات التهات التجارة

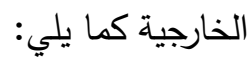

\section{4-1-4 المؤشرات الانتاجية والاقتصادية}

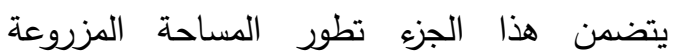
والانتاجية الفذانية والانتاج الكلي، التكاليف الكلية، الايراد

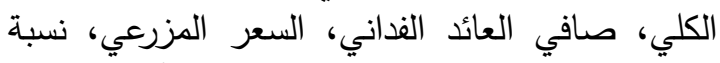

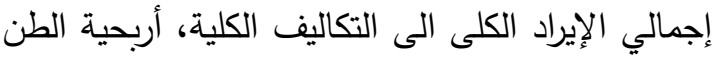

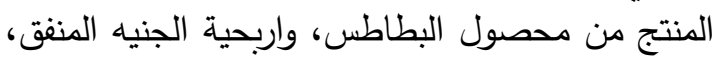

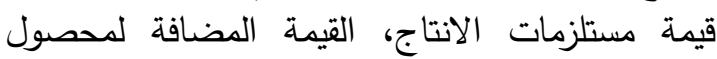

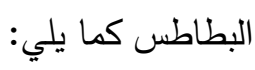

\section{- تطور المساحه المزروعة}

باستعراض البيانات الوراردة بالجدول رقم 1 تبين

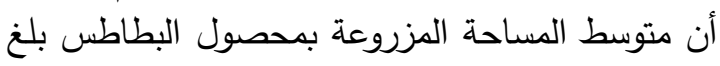

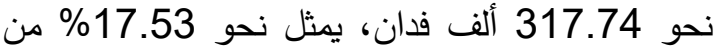

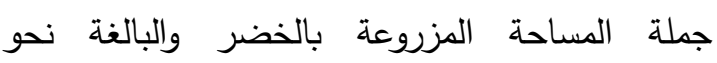
1785.14 الف فدان خلال الفترة (2000-2018) كما يلاحظ أيضاً أن هذه الرقعة كانت تتذبذب انخفاضاً
المحاصيل الخضرية الهامة فى مصر من حيث توافر

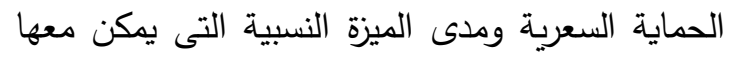

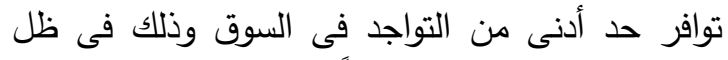

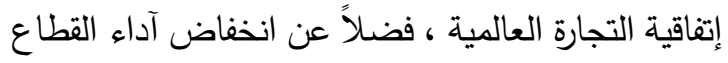

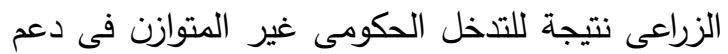

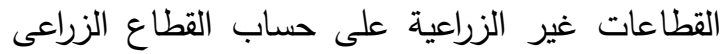

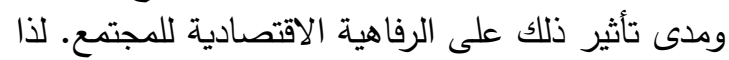

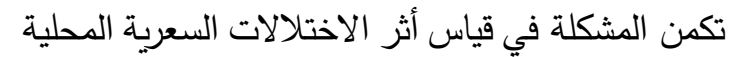

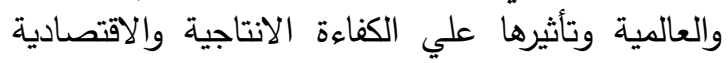

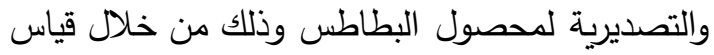

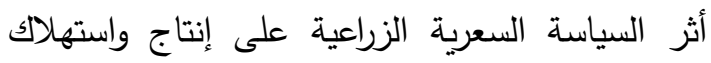

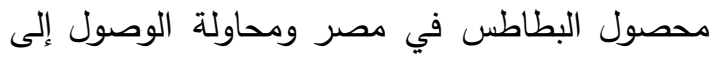

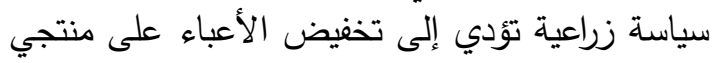

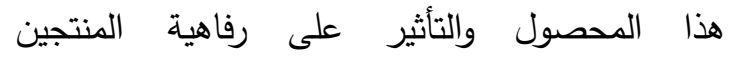
والمستهلكين وعلى حصيلة النقد الأجنبي.

\section{3 أهداف البحث}

يستهدف البحث دراسة اثر السياسات السعرية علي

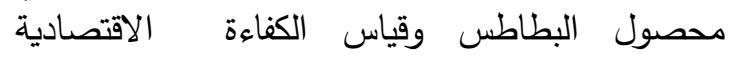

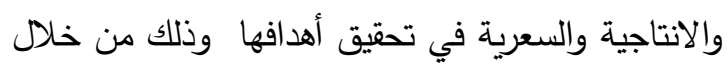
إلقاء الضوء على ما يلى: 1- التعرف علي المؤشرات الإنتاجية والاقتصادية

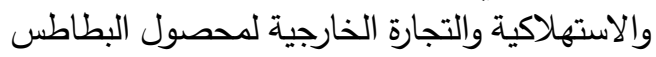
2- التعرف علي مدي إنحراف السعر الذي يحصل علية

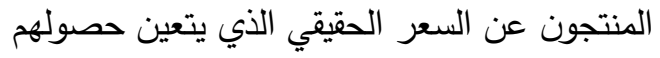

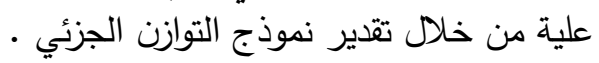

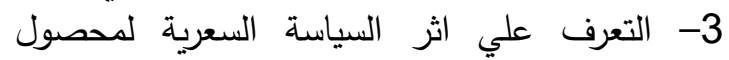

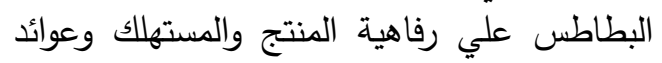

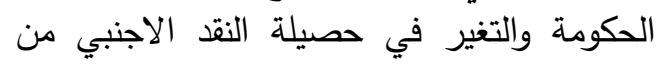
خلال تقدير نموذج التوازن الجزئي.

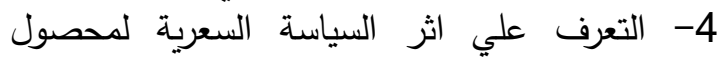

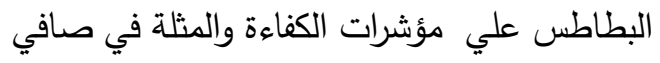

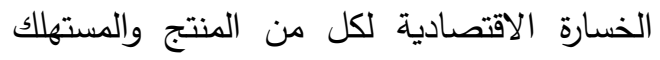
والمجتمع من خلال تقدير نموذج التوازن الجزئي. الطريقة البحثية ومصادر البيانات

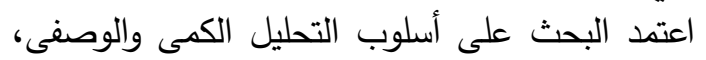
حيث استخدمت العديد من الأساليب الرياضية الرئية 
قدرها نحو 3190.54 الف طن، بمعدل زيادة بلغ نحو

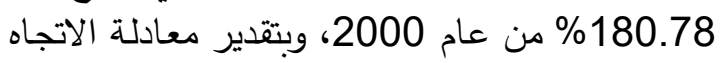

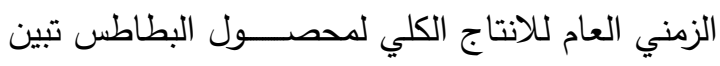
من المعادلة رقم (3) بالجدول رقم 2 زيادة الانتاج لئاج

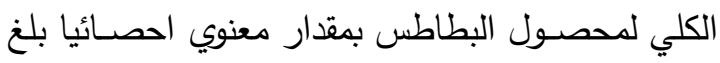

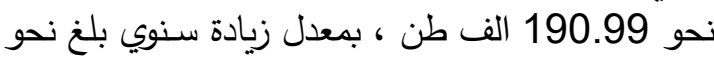

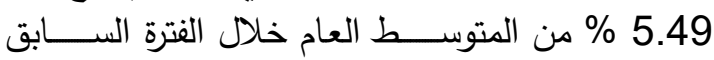
الاشارة اليها، وقد بلغ معامل التحديد نحو 0.490.

- تطور التكاليف الإنتاجية تبين من الجدول رقم 3 ان متوسط التكاليف الكلية بلغ نحو 9554.53 جنيها خلال الفترة (2000 النيا 2018)، وقد تراوحت التكاليف الكلية بين حد أدنى بلغ

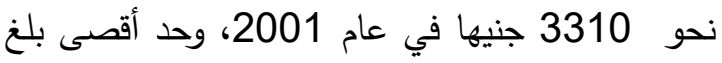

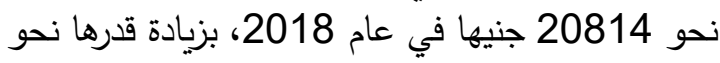

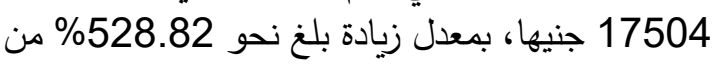
عام 2001. وبتقدير معادلة الاتجاه الزمني العام للتكاليف الكلية لمحصول البطاطس تبين من الكعادلة الكيادي رقم (1) بالجدول رقم 4 زيادة التكاليف الكلية من الكنالئ

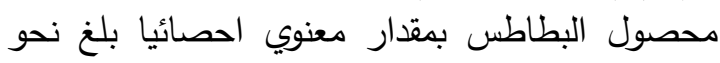

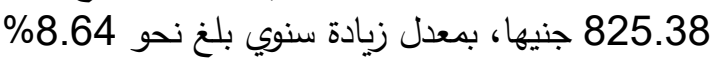
من الكتوسط العام خلال الفترة السابق الاثارة اليها، وقد بلغ معامل التحديد نحو 0.86.

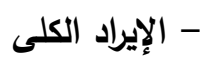
اتضح من الجدول رقم 3 أن متوسط الإيراد الكلى العلى

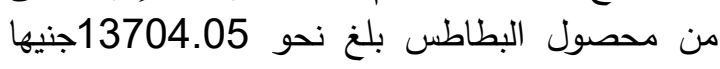
خلال الفترة (2000-2018)، وقد تراوح الايراد الكلي

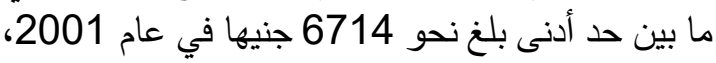

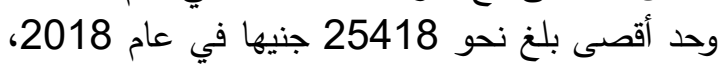
بزيادة قدرها نحو 18704 من جنيها، بمعدل زيادة بلغ نحو

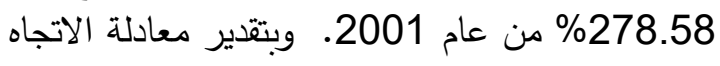

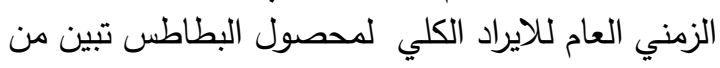
المعادلة رقم (2) بالجدول رقم 4 زيادة الايراد الكلي من لئل محصول البطاطس بمقدار معنوي احصائيا بلغ نحو

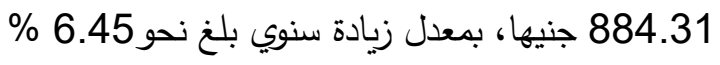
من المتوسط العام خلال الفترة السابق الآشارة اليها، وقد

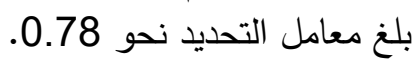

وارتفاعاً، وذلك بحد أدنى بلغ نحو 178.69 ألف فدان

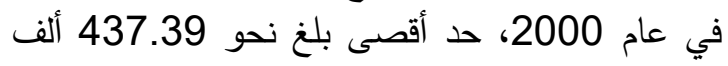
فدان في عام 2017، بزيادة قدرها نحو 258.7 الف بلف

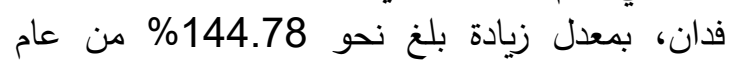
2000، وبتقدير معادلة الاتجاه الزمني العام للمساحة

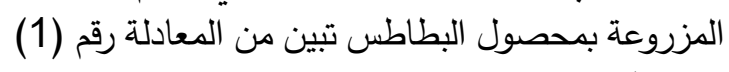

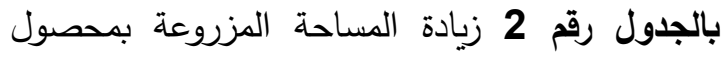
البطاطس بمقار معنوي احصائيا بلغ نحو 15.31 الفئ الفرون

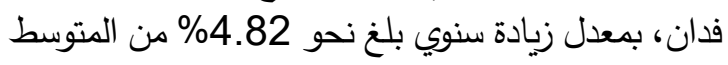

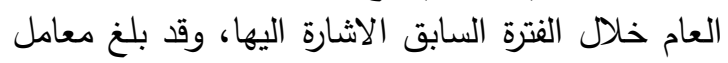

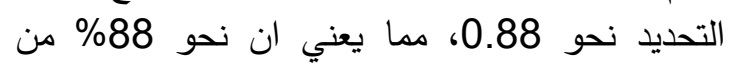

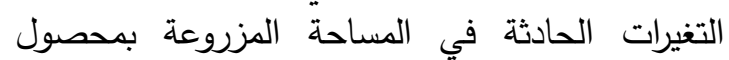
البطاطس تعزي الي التغيرات التي يعكسها عنصر لئرد

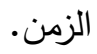

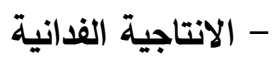
بإستعراض البيانات الوراردة بالجدول رقم 1 تبين أن النقان متوسط الانتاجية الفدانية لمحصول البطاطس بلغ بلغ نحون 10.82 طن خلال الفترة (2000-2018) ونلك بلك بحد أدنى بلغ نحو 9.88 طن في عام 2000، 2000، حد أقصى بـ بلغ نحو 11.68 طن في عام 2018 2018، بزيادة قدرها نحو

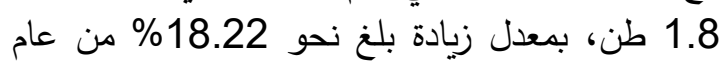
2000، وبتقدير معادلة الاتجاه الزمني العام للانتاجية عابح

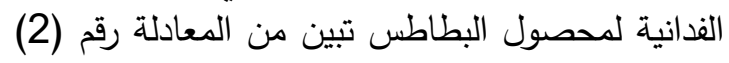

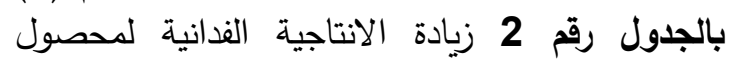

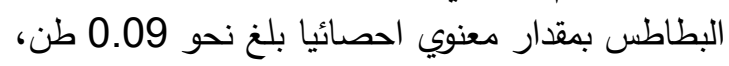

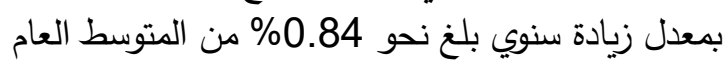
خلال الفترة السابق الاثشارة إليها، وقد بلغ معامل التحديد نحو0.90. بإبـــتعراض البيانات الوراردة بالجدول رقم 1 تبين

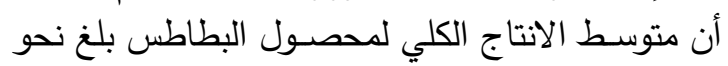

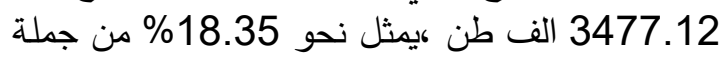
الانتاج الكلي للخضر والبالغة نحو 18971.52 الفئل 18918 الف

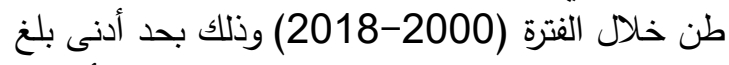

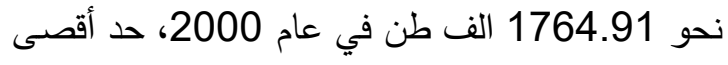
بلغ نحو 4955.45 الف طن في عام 2017، بزيادة 
جدول 1. تطور المساحة المزروعة والانتاجية الفدانية والإنتاج الكلى لمحصول البطاطس فى مصر خلال الفترة (2018-2000)

\begin{tabular}{|c|c|c|c|c|c|c|c|}
\hline \multirow{2}{*}{$\begin{array}{c}\text { \% } \\
\text { من التتاج } \\
\end{array}$} & \multicolumn{2}{|c|}{ الانتاج الكلي (الف طن) } & \multirow{2}{*}{ الإنتاجية الفدانية } & \multirow{2}{*}{\begin{tabular}{|c|} 
\% \\
الخضر مساحة \\
\end{tabular}} & \multicolumn{2}{|c|}{ 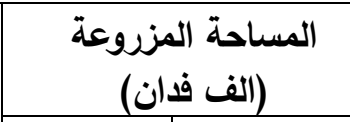 } & \multirow[t]{2}{*}{ السنوات } \\
\hline & الخضر & البطاطس & & & | الخضر & البطاطس & \\
\hline 12.28 & 14372.59 & 1764.91 & 9.88 & 12.93 & 1382.27 & 178.69 & 2000 \\
\hline 14.10 & 13500.03 & 1903.13 & 10.03 & 14.63 & 1296.78 & 189.76 & 2001 \\
\hline 13.79 & 14396.14 & 1985.32 & 10.10 & 14.24 & 1380.58 & 196.64 & 2002 \\
\hline 13.18 & 15476.53 & 2039.35 & 10.34 & 13.21 & 1493.31 & 197.25 & 2003 \\
\hline 16.37 & 15552.31 & 2546.61 & 10.27 & 17.68 & 1403.15 & 248.04 & 2004 \\
\hline 18.47 & 17145.38 & 3167.43 & 10.53 & 19.99 & 1504.00 & 300.66 & 2005 \\
\hline 12.88 & 17954.93 & 2312.79 & 10.50 & 14.03 & 1569.01 & 220.20 & 2006 \\
\hline 15.26 & 18092.68 & 2760.46 & 10.74 & 15.91 & 1615.51 & 257.03 & 2007 \\
\hline 16.59 & 21501.79 & 3567.05 & 10.89 & 17.10 & 1915.16 & 327.42 & 2008 \\
\hline 15.74 & 23247.40 & 3659.28 & 11.10 & 15.33 & 2151.39 & 329.72 & 2009 \\
\hline 17.06 & 21301.93 & 3634.22 & 10.86 & 15.85 & 2111.75 & 334.64 & 2010 \\
\hline 20.45 & 21217.49 & 4338.43 & 11.10 & 18.98 & 2058.67 & 390.81 & 2011 \\
\hline 21.10 & 22548.45 & 4758.04 & 11.28 & 20.38 & 2070.45 & 421.88 & 2012 \\
\hline 20.18 & 21131.03 & 4265.18 & 11.18 & 19.24 & 1982.56 & 381.38 & 2013 \\
\hline 21.15 & 21797.45 & 4611.07 & 11.26 & 19.29 & 2122.95 & 409.54 & 2014 \\
\hline 23.22 & 21338.41 & 4955.45 & 11.33 & 20.66 & 2116.68 & 437.39 & 2015 \\
\hline 20.54 & 20025.42 & 4113.44 & 10.92 & 18.97 & \begin{tabular}{|l|}
1985.84 \\
\end{tabular} & 376.63 & 2016 \\
\hline 24.89 & 19452.59 & 4841.04 & 11.67 & 22.13 & 1874.34 & 414.86 & 2017 \\
\hline 24.18 & 20026.31 & 4842.03 & 11.68 & 22.55 & 1883.21 & 424.61 & 2018 \\
\hline 18.35 & 18951.52 & 3477.12 & 10.82 & 17.53 & 1785.14 & 317.74 & المتوسط \\
\hline
\end{tabular}

المصدر: وزارة الزراعة واستصـلاح الاراضس، قطاع الشئون الاقتصادية، الإدارة المركزية للاقتصساد الزراعي، نشرة الاقتصـاد 
جدول 2. معادلات الاتجاة الزمني العام لتطور المساحة المزروعة والانتاجية الفدانية والانتاج الكلي لمجصول ألبطاطس فى مصر خلال الفترة (2000-2018)

\begin{tabular}{|c|c|c|c|c|c|c|}
\hline معدل الزّنيادة & المتوسط & $\mathbf{F}$ & $\mathbf{R}^{2}$ & المعادلات & البيان & p \\
\hline 4.82 & 317.74 & 129.64 & 0.88 & $\begin{array}{l}\bar{Y}=164.67+15.31 x \\
(10.74)^{* *}(11.39)^{* *}\end{array}$ & (الفساحة المزان) & 1 \\
\hline 0.84 & 10.82 & 154.28 & 0.90 & $\begin{array}{l}Y=9.20+0.09 \mathrm{X} \\
(119.41)^{* *}(12.42)^{* *}\end{array}$ & $\begin{array}{r}\text { الانتاجية الفذان) } \\
\text { (طدانية }\end{array}$ & 2 \\
\hline 5.49 & 3477.12 & 146.64 & 0.90 & $\begin{array}{l}Y=1567.24+190.99 x \\
(8.72)^{* *}(12.11)^{* *}\end{array}$ & (الأنتاج طن/الكلي & 3 \\
\hline
\end{tabular}

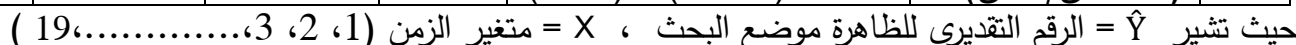

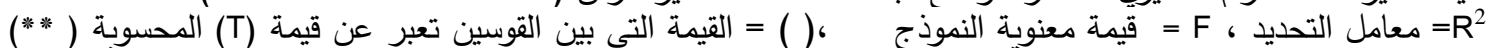

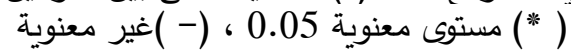

0.01 مستوى معنوية

المصدر : جمعت وحسبت من الجداول رقم (1).

جدول 3. تطور التكاليف الكلية والإيراد الكلى وصافى العائد الفدانى والسعر المزرعي ونسبة العائد للتكاليف وأربحية الجنية المنفق واربحية الطن المنتج لمحصول البطاطس خلال الفترة (2000-2018)

القيمة: بالجنيه

\begin{tabular}{|c|c|c|c|c|c|c|c|}
\hline اربحية الطن المنتج & اربحية الجنيه & نلتبكة العائد & المزرعى & العائد الفدانىى & الايراد & الانتالية & السنوات \\
\hline 359.92 & 1.05 & 2.05 & 627 & 3556 & 6934 & 3378 & 2000 \\
\hline 339.38 & 1.03 & 2.03 & 628 & 3404 & 6714 & 3310 & 2001 \\
\hline 318.22 & 0.86 & 1.86 & 636 & 3214 & 6946 & 3732 & 2002 \\
\hline 333.66 & 0.77 & 1.77 & 717 & 3450 & 7954 & 4504 & 2003 \\
\hline 206.13 & 0.35 & 1.35 & 696 & 2117 & 8138 & 6021 & 2004 \\
\hline 175.12 & 0.29 & 1.29 & 694 & 1844 & 8196 & 6352 & 2005 \\
\hline 291.71 & 0.44 & 1.44 & 852 & 3063 & 10073 & 7010 & 2006 \\
\hline 619.27 & 0.83 & 1.83 & 1212 & 6651 & 14665 & 8014 & 2007 \\
\hline 484.30 & 0.56 & 1.56 & 1217 & 5274 & 14616 & 9342 & 2008 \\
\hline 583.42 & 0.68 & 1.68 & 1329 & 6476 & 15967 & 9491 & 2009 \\
\hline 601.10 & 0.69 & 1.69 & 1345 & 6528 & 15925 & 9397 & 2010 \\
\hline 696.67 & 0.71 & 1.71 & 1701 & 7733 & 18694 & 10962 & 2011 \\
\hline 278.46 & 0.28 & 1.28 & 1165 & 3141 & 14477 & 11336 & 2012 \\
\hline 301.52 & 0.31 & 1.31 & 1182 & 3371 & 14360 & 10989 & 2013 \\
\hline 297.42 & 0.30 & 1.30 & 1193 & 3349 & 14402 & 11053 & 2014 \\
\hline 300.09 & 0.31 & 1.31 & 1185 & 3400 & 14488 & 11088 & 2015 \\
\hline 280.49 & 0.22 & 1.22 & 1414 & 3063 & 17002 & 13939 & 2016 \\
\hline 394.52 & 0.22 & 1.22 & 2006 & 4604 & 25408 & 20804 & 2017 \\
\hline 394.18 & 0.22 & 1.22 & 2007 & 4604 & 25418 & 20814 & 2018 \\
\hline 381.87 & 0.53 & 1.53 & 1147.68 & 4149.58 & 13704.05 & 9554.53 & المتوسط \\
\hline
\end{tabular}

المصدر: وزارة الزراعة واستصلاح الاراضى، قطاع الثئون الاقتصادية، الإدارة المركزية للاقتصاد الزراعى، نشرة الاقتصاد 
جدول 4. معادلات الاتجاة الزمني العام للتكاليف الكلية والايراد الكلي وصافي العائد الفداني والسعر المزرعي لمحصول البطاطس فى مصر خلال الفترة (2000-2018)

\begin{tabular}{|c|c|c|c|c|c|c|}
\hline معدل الزيادة & المتوسط & $\mathbf{F}$ & $\mathbf{R}^{2}$ & المعادلات & البيان & م \\
\hline 8.64 & 9554.53 & 102.72 & 0.86 & $\begin{array}{c}\hat{Y}=1300.74+825.38 x \\
{ }^{* *}(1.40)^{-}(10.14)\end{array}$ & التكاليف الكلية & 1 \\
\hline 6.45 & 13704.05 & 60.09 & 0.78 & $\begin{array}{c}\hat{Y}=4860.91+884.31 x \\
(3.74)^{\star *}(7.75)^{\star *}\end{array}$ & الايراد الكلي & 2 \\
\hline- & 4149.58 & 0.72 & 0.25 & $\begin{array}{c}\hat{Y}=3560.19+58.94 x \\
(4.49)^{\star *}(0.85)-\end{array}$ & الفاداني (جنية) & 3 \\
\hline 5.83 & 1147.68 & 50.19 & 0.75 & $\begin{array}{l}\hat{Y}=477.96+66.97 x \\
(4.43)^{\star *}(7.08)^{\star *}\end{array}$ & السعر المزرعي & 4 \\
\hline
\end{tabular}

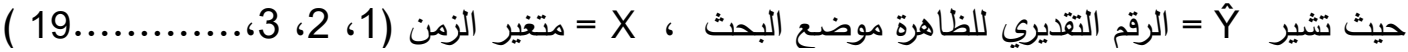

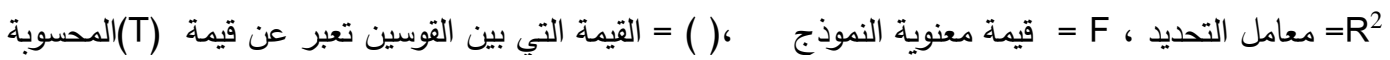

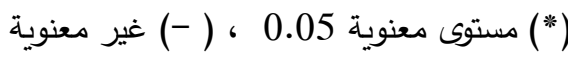

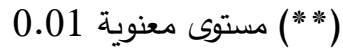

المصدر : جمعت وحسبت من الجداول رقم (3).

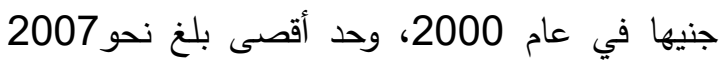

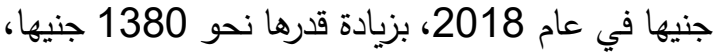

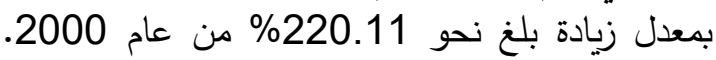
وبتقدير معادلة الاتجاه الزمني العام للسعر المزرعي لمحصول البطاطس تبين من المعادلة رقم (4) الواردة الإدي

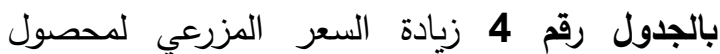

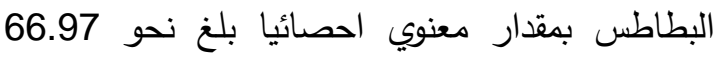

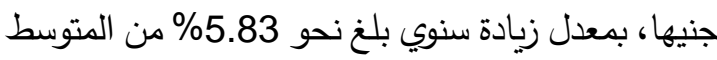
العام خلال الفترة السابق الاشارة اليها، وقد بلغ معامل التحديد نحو 0.75.

- نسبة إجمالي الإيراد الكلى الى التكاليف الكلية وهذا المقياس عبارة عن النسبة بين قيمة الإنتاج الى الإلى الإلى الإلى تكلفة عناصر الإنتاج المستخدمة فى العملية الإنتاجية، أى أن هذا المعيار يتناول شطري العملية الإنتاجية في الإنياتية

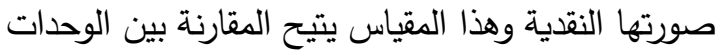

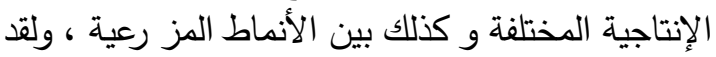

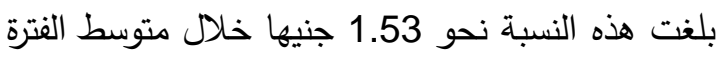
(2000-2000) كما فى الجدول رقم 3.

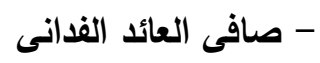
اتضح من الجدول رقم 3 أن متوسط صافي العائد الفداني من محصول البطاطس بلغ نحو 4149.58 جنيها خلال الفترة (2000-2018)، وقد تذبذب صافي التبان

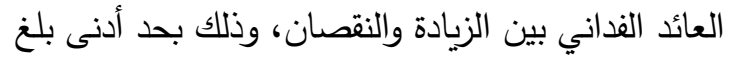

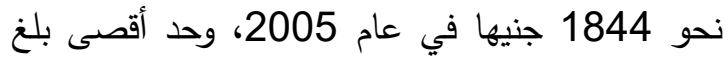

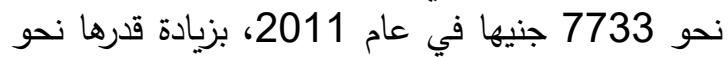

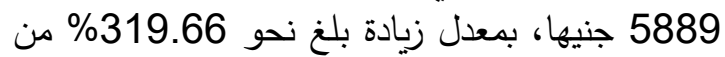

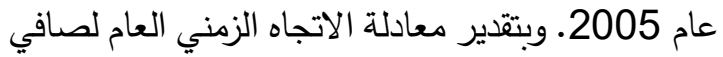
العائد الفداني لمحصول البطاطس تبين من المعادلة رقم

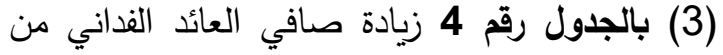

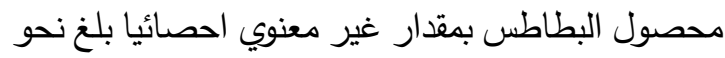
205.6 جنيها، مما يعني الثبات النسبي لصافي العائد الصنائ

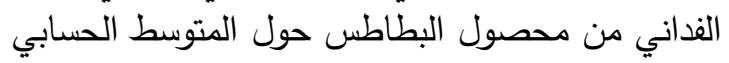
خلال الفترة السابق الاشارة اليها.

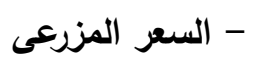

تبين من الجدول رقم 3 أن متوسط السعر المزرعي

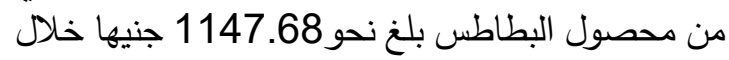
الفترة (2000-2018)، وذلك بحد أدنى بلغ نحو 627 
خلال الفترة (2000-2018)، وقد تراوحت القيمة المضافة من محصول البطاطس ما بين حد أدنى بلغ الغن

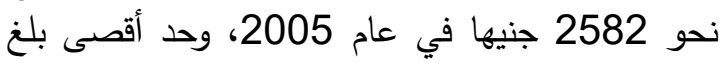

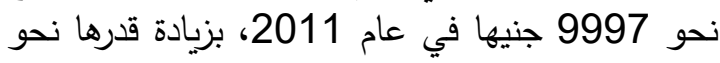

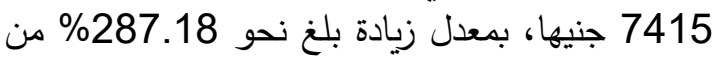
عام 2005. وبتقدير معادلة الاتجاه الزمني العام للقيمة

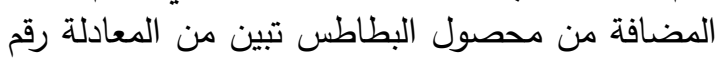
(2) الواردة بالجدول رقم 6 زيادة القيمة المضافة من المعادلة رن

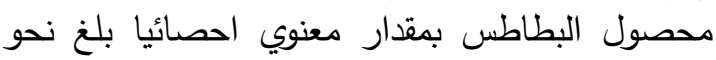

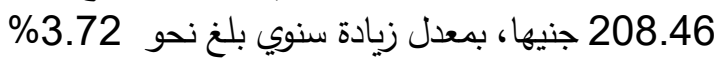
من المتوسط العام خلال الفترة السابق الاشارة اليها، وقد

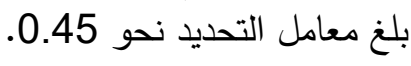

- نسبة القيمة المضافة الي مستلزمات الانتاج من

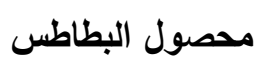

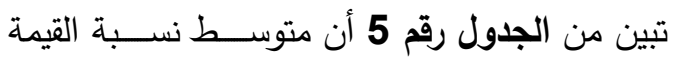
المضافة الي مستلزمات الانتاج من محصول البون البطاطس بلغ نحو 79.92\% خلال الفترة (2000-2018)

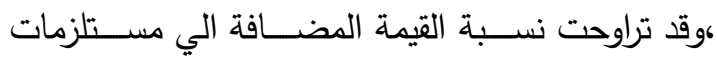

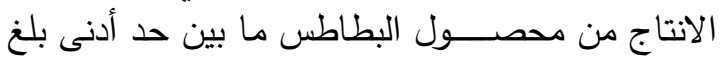

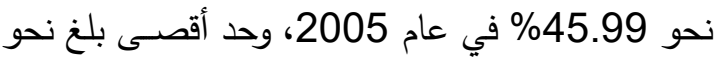

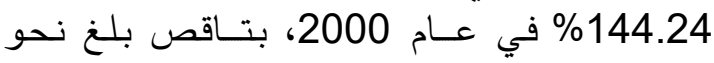

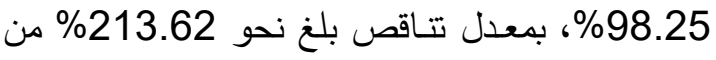
عام 2005. وبتقدير معادلة الاتجاه الزمني العام لنسبة

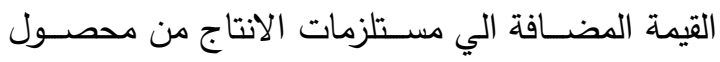
البطاطس تبين من الدعادلة رقم (3) الواردة بالجدول

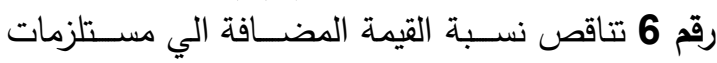
الانتاج من محصول البطاطس بمقدار معنوي احصائيا

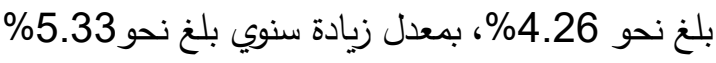
من المتوسط العام خلال الفترة السابق الاشارة اليها، وقد

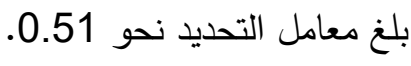

- اربحية الطن المنتج من محصول البطاطس

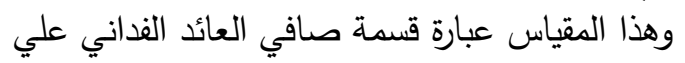
إنتاجية الفدان بالطن وقد بلغت نحو 381.87 جنيهان الفيان للطن خلال متوسط الفترة (2000-2018) كما فى الجدول رقم 3. ويتم الحصول على هذا المعيار بقسمة صافي العائد

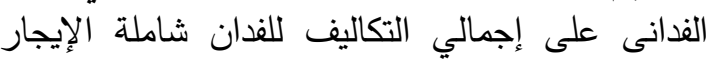
والأجور وغيرها، وتعكس زيادة هذا المعيار ارتفاع ربحية الإنية

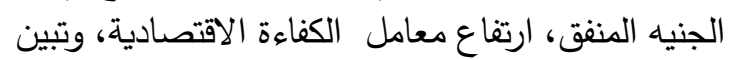
من الجدول رقم 3 أن متوسط أربحية الجنيه الهنفق في الهئ

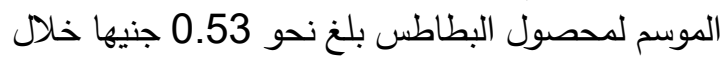
متوسط الفترة (2000-2018). - قيمة مستلزمات الانتاج تبين من الجدول رقم 5 أن متوسط قيمة مستلزمات

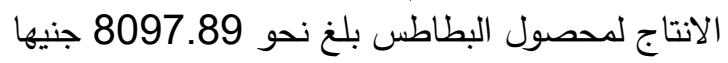

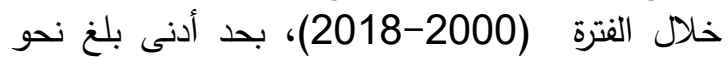

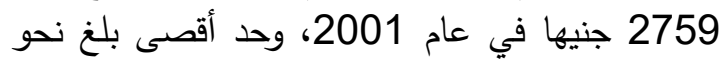

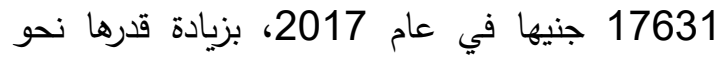

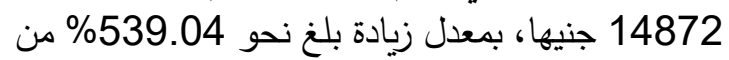
عام 2001 ـ وبتقدير معادلة الاتجاه الزمني العام لقيمة

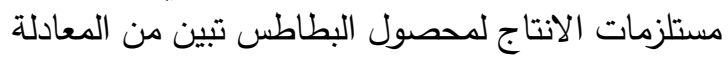

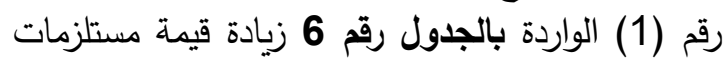

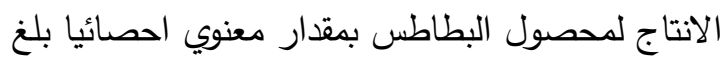

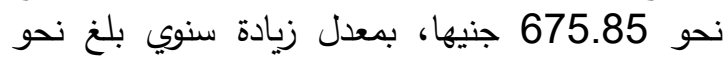
8.35\% من المتوسط العام خلال الفنترة السابق الاشارة

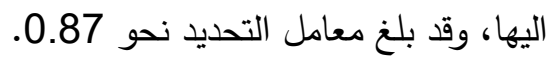

- القيمة المضافة لمحصول البطاطس تبين من الجدول رقم 5 أن متوسط القيطة النيطة المضافة من محصول البطاطس بلغ نحو 5606.16 ند 5 نيها 
جدول 5. تطور قيمة الانتاج الكلي والقيمة المضافة الفدانية ومستلزمات الانتاج لمحصول البطاطس خلال الفترة (2018-2000)

\begin{tabular}{|c|c|c|c|c|}
\hline مستالقيمة المضافة من & القيمة المضافة(جنية) & قيمة مستلزمات الانتاج (جنية) & $\begin{array}{c}\text { الايراد الكلي (قيمة } \\
\text { (جنتية) } \\
\text { (جنانة) }\end{array}$ & السنوات \\
\hline 144.24 & 4095 & 2839 & 6934 & 2000 \\
\hline 143.35 & 3955 & 2759 & 6714 & 2001 \\
\hline 118.36 & 3765 & 3181 & 6946 & 2002 \\
\hline 105.05 & 4075 & 3879 & 7954 & 2003 \\
\hline 53.11 & 2823 & 5315 & 8138 & 2004 \\
\hline 45.99 & 2582 & 5614 & 8196 & 2005 \\
\hline 62.31 & 3867 & 6206 & 10073 & 2006 \\
\hline 110.13 & 7686 & 6979 & 14665 & 2007 \\
\hline 81.79 & 6576 & 8040 & 14616 & 2008 \\
\hline 94.36 & 7752 & 8215 & 15967 & 2009 \\
\hline 97.92 & 7879 & 8046 & 15925 & 2010 \\
\hline 114.95 & 9997 & 8697 & 18694 & 2011 \\
\hline 46.06 & 4565 & 9912 & 14477 & 2012 \\
\hline 50.79 & 4837 & 9523 & 14360 & 2013 \\
\hline 50.27 & 4818 & 9584 & 14402 & 2014 \\
\hline 51.88 & 4949 & 9539 & 14488 & 2015 \\
\hline 50.91 & 5736 & 11266 & 17002 & 2016 \\
\hline 44.11 & 7777 & 17631 & 25408 & 2017 \\
\hline 52.80 & 8783 & 16635 & 25418 & 2018 \\
\hline 79.92 & 5606.16 & 8097.89 & 13704.05 & المتوسط \\
\hline
\end{tabular}

المصدر : وزارة الزراعة واستصلاح الاراضى، قطاع الثئون الاقتصادية، الإدارة المركزية للاقتصاد الزراعى، نشرة الاقتصاد 
جدول 6. معادلات الاتجاة الزمني العام لتطور القيمة المضافة الفدانية ومستلزمات الانتاج لمحصول البطاطس خلال الفترة (2000-2018) (200)

\begin{tabular}{|c|c|c|c|c|c|c|}
\hline معدل الزيادة & المتوسط & $\mathbf{F}$ & $\mathbf{R}^{2}$ & المعادلات & البيان & 5 \\
\hline 8.35 & 8097.89 & 109.82 & 0.87 & $\begin{array}{c}\hat{Y}=1339.37+675.85 x \\
(1.82)^{-}(10.48)^{* *}\end{array}$ & $\begin{array}{c}\text { قيمة مستلزمات الانتاج } \\
\text { (جنيه) }\end{array}$ & 1 \\
\hline 3.72 & 5606.16 & 7.29 & 0.45 & $\begin{array}{c}\hat{Y}=3521.54+208.46 \mathrm{x} \\
(4.01)^{\star *}(2.70)^{\star *}\end{array}$ & 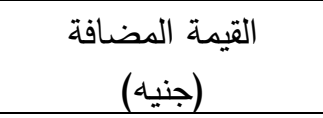 & 2 \\
\hline 5.33 & 79.92 & 15.51 & 0.51 & $\begin{array}{l}\hat{Y}=122.48-4.26 x \\
(9.94)^{* *}(-3.94)^{* *}\end{array}$ & \% مستلزمات المضافة من الانتاج & 3 \\
\hline
\end{tabular}

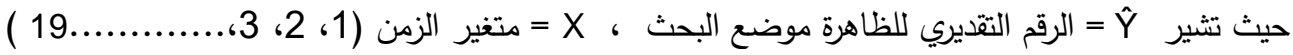

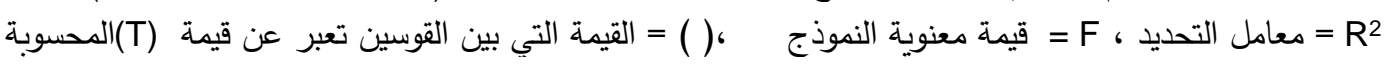

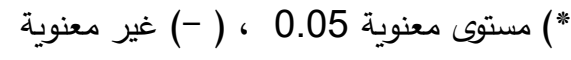

0.010

المصدر : جمعت وحسبت من الجداول رقم (5).

- كمية الفاقد تبين من الجدول رقم 7 أن متوسط كمية الفاقد من محصول البطاطس بلغ نحو 425.32 الف طن خن خلال

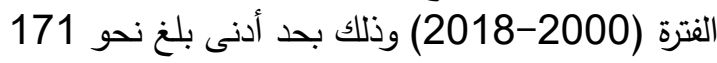

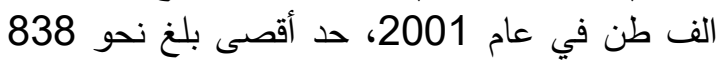

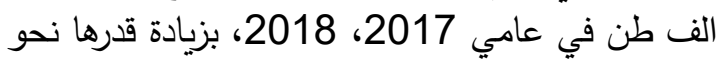

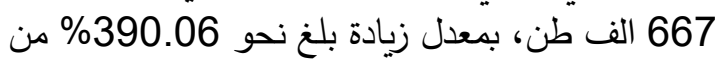

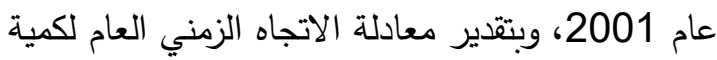

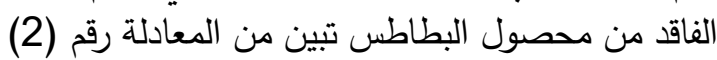
بالجدول رقم 8 زيادة كمية الفاقد من محصول من البط البطاطس

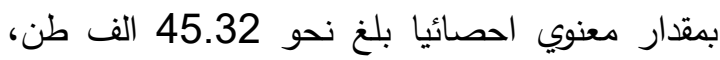

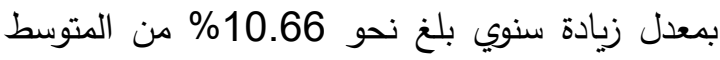
العام خلال الفترة السابق الاشارة اليها، وقد بلغ معامل

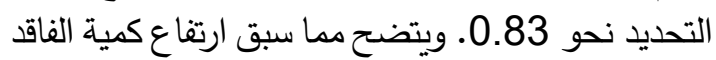

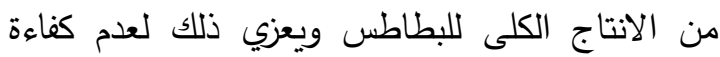

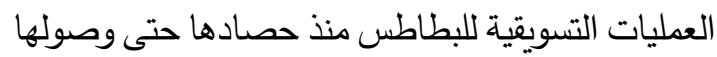

المستهلك.
4-2- - 2- مؤشرات الاستهلاك

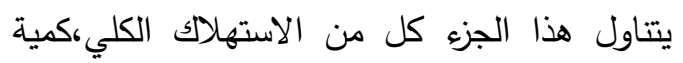

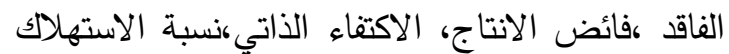

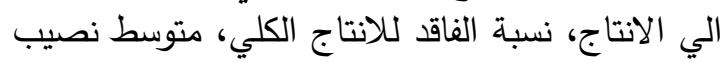

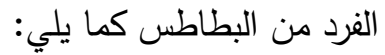
تبين من الجدول رقم 7 أن متوسط الاستهلاك الكلي

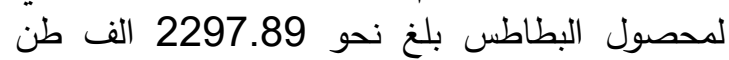
خلال الفترة (2000-2018) وذلك بحد أدنى بلغ نحو لعن

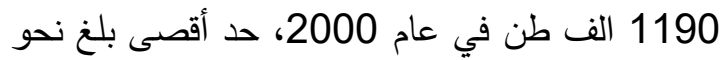

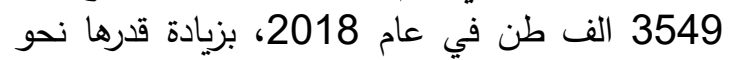

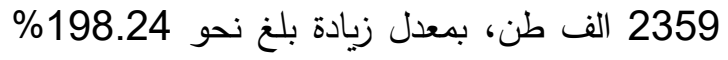
من عام 2000، وبتقدير معادلة الاتجاه الزمني العام لبول للاستهلاك الكلي لمحصول البطاطس تبين من المعادلة

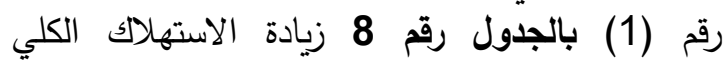
لمحصول البطاطس بمقدار معنوي احصائيا بلغ نحو

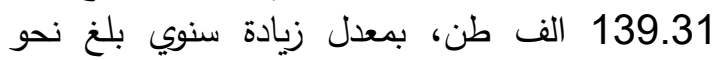

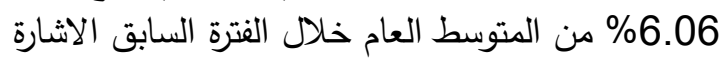
اليها، وقد بلغ معامل التحديد نحو 0.063. 
جدول 7. تطور الاستهلاك الكلي وكمية الفاقد وفائض الانتاج والاكتفاء الذاتي متوسط نصيب الفرد ونسبة الاستهلاكك الي الانتاج و نسبة الفاقد الي الانتاج للحصول البطاطس خلال الفترة (2000-2018)

\begin{tabular}{|c|c|c|c|c|c|c|c|c|}
\hline نصيب الفرد & \% الانتاج الي & الاسي الانتاج الاستهلا & الأاتيفاء & فائض الإنتاج & كمية الفاقد & الاستهلاك (الكلي & (الانتاج الكلي & السنوات | \\
\hline 18.63 & 11.22 & 67.43 & 148.31 & 574.91 & 198 & 1190 & 1764.91 & 2000 \\
\hline 20.60 & 8.99 & 70.57 & 141.71 & 560.13 & 171 & 1343 & 1903.13 & 2001 \\
\hline 20.46 & 8.92 & 68.55 & 145.87 & 624.32 & 177 & 1361 & 1985.32 & 2002 \\
\hline 19.85 & 9.32 & 66.10 & 151.29 & 691.35 & 190 & 1348 & 2039.35 & 2003 \\
\hline 22.68 & 7.03 & 61.73 & 162.00 & 974.61 & 179 & 1572 & 2546.61 & 2004 \\
\hline 28.91 & 5.71 & 64.56 & 154.89 & 1122.43 & 181 & 2045 & 3167.43 & 2005 \\
\hline 19.93 & 9.47 & 62.22 & 160.72 & 873.79 & 219 & 1439 & 2312.79 & 2006 \\
\hline 23.78 & 10.32 & 63.43 & 157.65 & 1009.46 & 285 & 1751 & 2760.46 & 2007 \\
\hline 31.32 & 5.63 & 66.05 & 151.40 & 1211.05 & 201 & 2356 & 3567.05 & 2008 \\
\hline 32.69 & 6.70 & 68.73 & 145.50 & 1144.28 & 245 & 2515 & 3659.28 & 2009 \\
\hline 30.34 & 9.08 & 65.74 & 152.12 & 1245.22 & 330 & 2389 & 3634.22 & 2010 \\
\hline 27.78 & 8.11 & 51.49 & 194.20 & 2104.43 & 352 & 2234 & 4338.43 & 2011 \\
\hline 30.50 & 11.92 & 52.86 & 189.19 & 2243.04 & 567 & 2515 & 4758.04 & 2012 \\
\hline 34.22 & 14.51 & 61.80 & 161.81 & 1629.18 & 619 & 2636 & 4265.18 & 2013 \\
\hline 35.69 & 18.00 & 70.01 & 142.85 & 1383.07 & 830 & 3228 & 4611.07 & 2014 \\
\hline 34.62 & 16.67 & 64.58 & 154.86 & 1755.45 & 826 & 3200 & 4955.45 & 2015 \\
\hline 36.53 & 20.30 & 83.87 & 119.23 & 663.44 & 835 & 3450 & 4113.44 & 2016 \\
\hline 36.70 & 17.31 & 73.10 & 136.79 & 1302.04 & 838 & 3539 & 4841.04 & 2017 \\
\hline 36.44 & 17.31 & 73.30 & 136.43 & 1293.03 & 838 & 3549 & 4842.03 & 2018 \\
\hline 28.51 & 11.40 & 66.11 & 152.99 & 1179.22 & 425.32 & 2297.89 & 3477.12 & المتوسط \\
\hline
\end{tabular}

المصدر : 1 - وزارة الزراعة واستصلاح الاراضى، قطاع الثئون الاقتصادية، الإدارة المركزية للاقتصاد الزراعي، نشرة

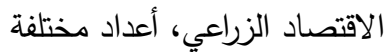

http//www.capmas.gov.org. 2

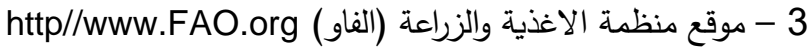


جدول 8. معادلات الاتجاة الزمني العام لتطور الاستهلاك الكلي وكمية الفاقد وفائض الانتاج والاكتفاء الذاتي متوسط نصيب الفرد لمحصول البطاطس خلال الفترة (2000-2018)

\begin{tabular}{|c|c|c|c|c|c|c|}
\hline معدل الزيادة او النقص & المتوسط & $\mathbf{F}$ & $\mathbf{R}^{2}$ & المعادلات & البيان & م \\
\hline 6.06 & 2297.89 & 228.91 & 0.93 & $\begin{array}{c}\hat{Y}=904.82+139.31 x \\
(6.82)^{* *}(15.13)^{* *}\end{array}$ & 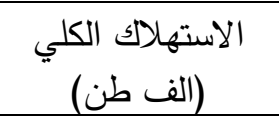 & 1 \\
\hline 10.66 & 425.32 & 85.43 & 0.83 & $\begin{array}{c}\hat{Y}=27.88+45.32 x \\
(0.50)^{-}(9.24)^{* *}\end{array}$ & (الف طمنة الفاقد) & 2 \\
\hline 4.38 & 1179.22 & 9.23 & 0.45 & $\begin{array}{c}\hat{Y}=662.42+51.68 x \\
(3.42)^{\star *}(3.04)^{\star \star}\end{array}$ & $\begin{array}{l}\text { فائض الانتاج } \\
\text { (الف طن) }\end{array}$ & 3 \\
\hline 0.25 & 152.99 & 4.28 & 0.40 & $\begin{array}{l}\hat{Y}=156.85-0.39 x \\
(18.76)^{\star *}(-2.07)^{*}\end{array}$ & \%الاكتفاء الذاتي & 4 \\
\hline 0.40 & 66.11 & 4.06 & 0.43 & $\begin{array}{c}\hat{Y}=63.49+0.26 x \\
(18.47)^{\star *}(2.01)^{*}\end{array}$ & $\begin{array}{l}\text { \%الاستهلاك الي الانتاج } \\
\text { \% }\end{array}$ & 5 \\
\hline 5.30 & 11.40 & 20.50 & 0.55 & $\begin{array}{l}\hat{Y}=5.40+0.60 x \\
(3.58)^{\star \star}(4.53)^{\star \star}\end{array}$ & \%الفاقد الي الانتاج & 6 \\
\hline 3.79 & 28.51 & 98.11 & 0.85 & $\begin{array}{c}\hat{Y}=17.72+1.08 x \\
(14.26)^{* *}(9.90)^{* *}\end{array}$ & متوسط نصيب الفرد & 7 \\
\hline
\end{tabular}

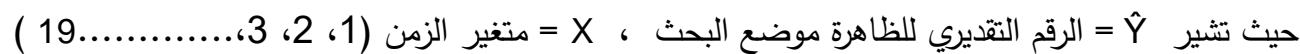

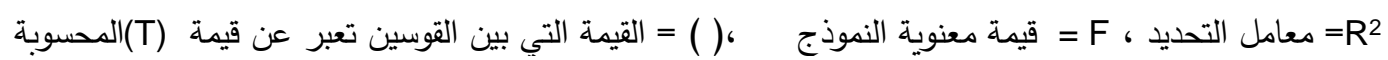

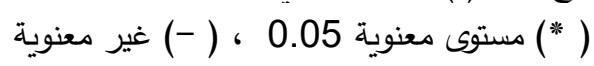

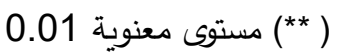
المصدر : جمعت وحسبت من الجداول رقم (7).

يمكن تصديره للخارج ومن ثم لابد من البحث عن أسواق تستوعب هذا الفائض لزيادة حصيلة الدولة من لإند النقد النداق الأجنبي. - الاكتفاء الذاتي تبين من الجدول رقم 7 أن متوسط الاكتفاء الذاتي

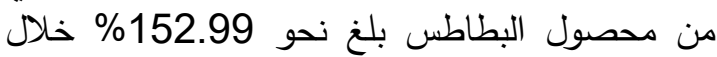
الفترة (2000-2018) وقد تذبذ الاكتفاء الذلتي من لئن

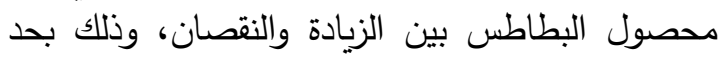

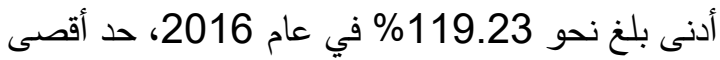

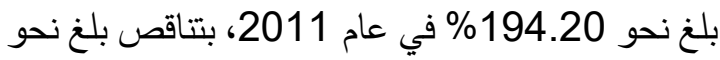

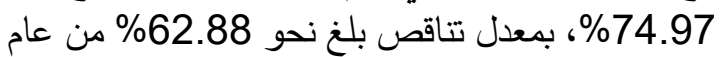
2016، وبتقدير معادلة الاتجاه الزمني العام للاكتفاء الذاتي من محصول البطاطس تبين من المعادلة رقم (4) بالجدول رقم 8 تناقص الاكتفاء الذاتي من محصول من لمعادل

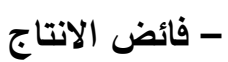
تبين من الجدول رقم 7 أن متوسط فائض الانتاج

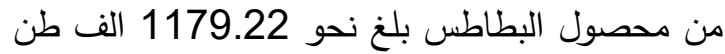
خلال الفترة (2000-2018) وذلك بحد أدنى بلغ نحو لحو لحن

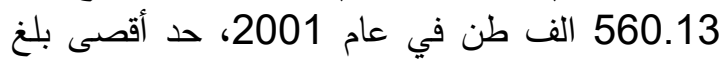

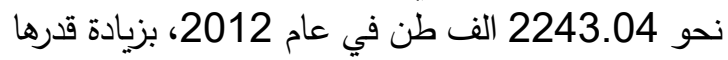

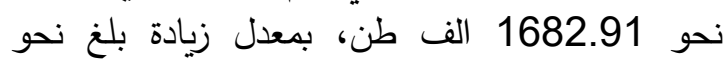

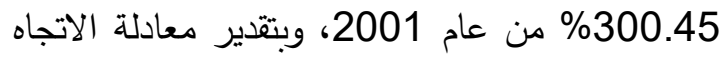
الزمني العام لفائض الانتاج من محصول

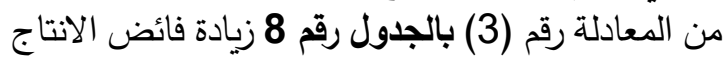

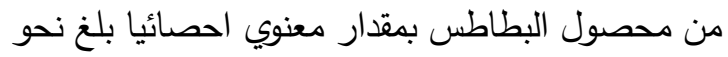

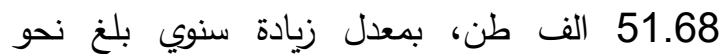
4.38 من المتوسط العام خلال الفترة السابق الاشارة اليها، وقد بلغ معامل التحديد نحو يعنى أن هناك فائضا فى الانتاج فى كل سنوات البحث 
18.63 كجم/سنة في عام 2000، حد أقصى بلغ نحو 36.70

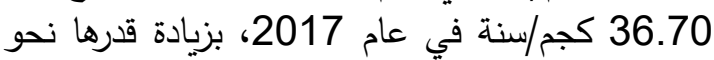

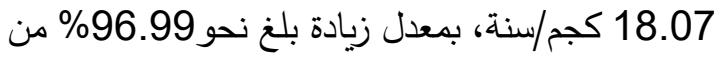

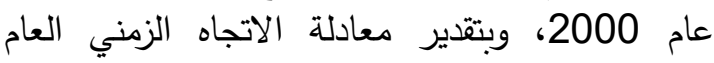

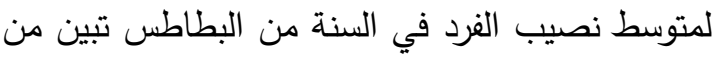

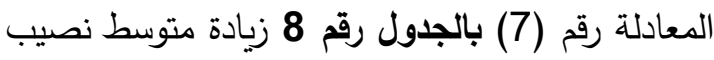

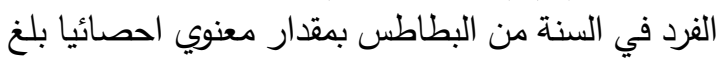

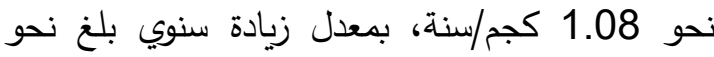
3.79 من المتوسط العام خلال الفترة السابق الاشارة بادئ اليها، وقد بلغ معامل التحديد نحو 0.85.

4-3- مؤشرات التجارة الخارجية يتضمن هذا الجزء كل من كمية وقيمة الصادرات

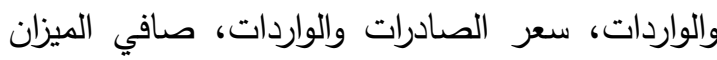

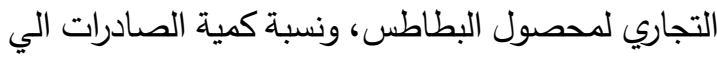
الانتاج الكلي كما يلي: اليطول تبين من الجدول رقم 9 أن متوسط كمية الصادرات من محصول البطاطس بلغ نحو

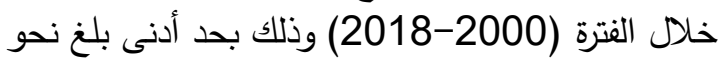
156.63 الف طن في عام 2000، حد أقصى بلغ

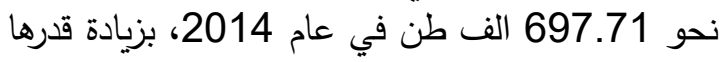

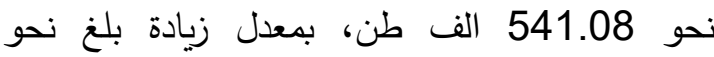
345.45 من عام 2000، وبتقدير معادلة الاتجاه

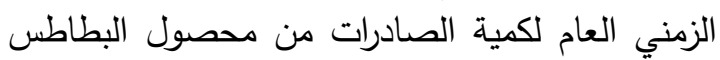

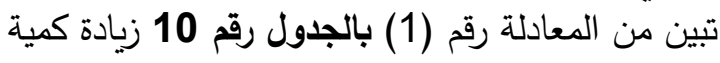

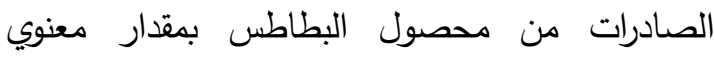

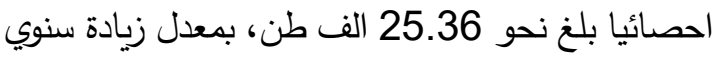

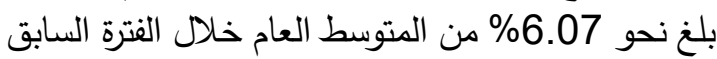

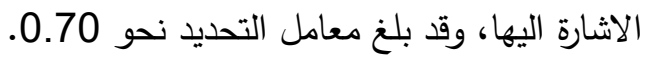

- قيمة الصادرات تبين من الجدول رقم 9 أن متوسط قيمة الصادرات من محصول البطاطس بلغ نحو 145.63 مليون دون دونار خلال الفترة (2000-2018) وذلك بحد أدنى بلغ نحو

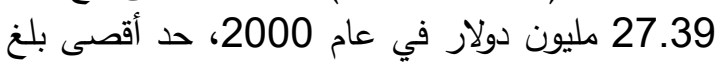

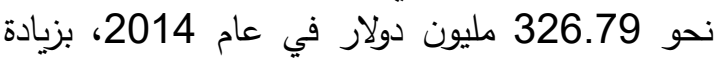
قدرها نحو 299.4 مليون دولار ، بمعدل زيادة بلغ نحو بزياد

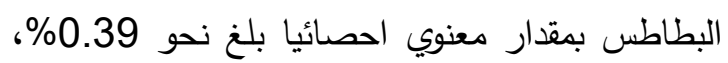

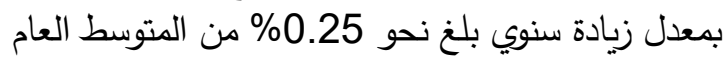
خلال الفترة السابق الاشارة اليها، وقد بلغ معامل من التحل التحديد نحو 0.40.

- نسبة الاستهلاك الي الانتاج من محصول البطاطس

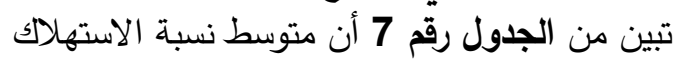
الي الانتاج من محصول البطاطس بلغ نحو خلال الفترة (2000-2018) وذلك بحد أدنى بلغ نحو \%1.49 في عام 2011، حد أقصى بلغ نحو 2016.87

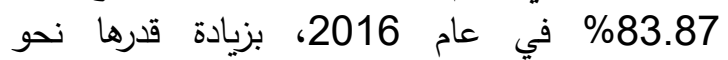

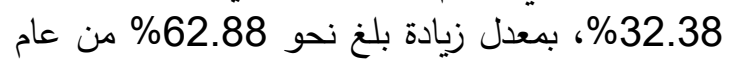
2011، وبتقدير معادلة الاتجاه الزمني العام لنسبة الاستهلاك الي الانتاج من محصول البطاطس تبين من الجنان

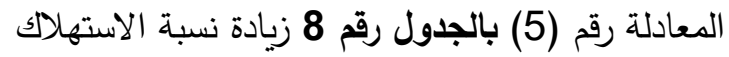

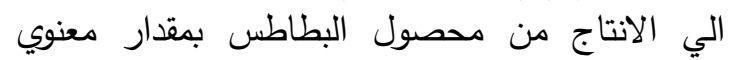

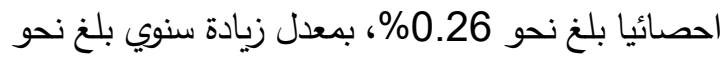

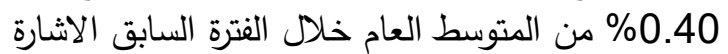

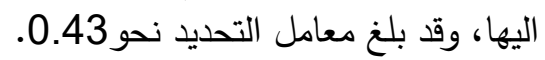

- نسبة كمية الفاقد الي الانتاج من محصول البطاطس تبين من الجدول رقم 7 أن متوسط نسبة كمية الفاقد الي الانتاج من محصول البطاطس بلغ نحو

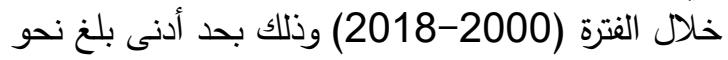

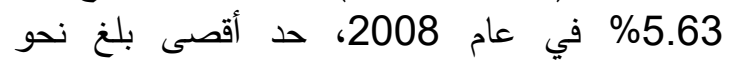

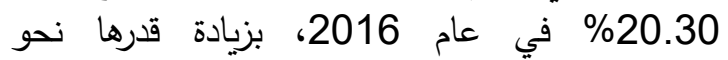

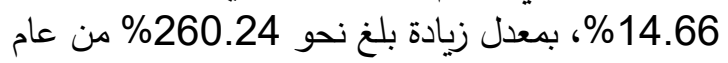
2008، وبتقدير معادلة الاتجاه الزمني العام لنسبة كمية

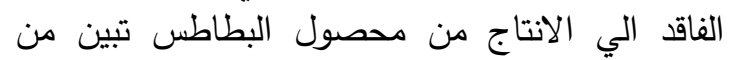
المعادلة رقم (6) بالجدول رقم 8 زيادة نسبة كمية الفاقد لئد

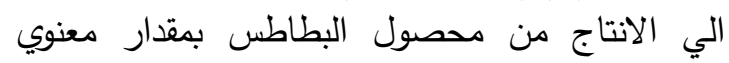

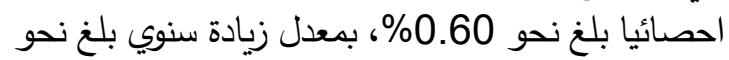
5.30 \% من المتوسط العام خلال الفترة السابق الاشارة اليها، وقد بلغ معامل التحديد نحو 0.55.

\footnotetext{
- متوسط نصيب الفرد في السنة من البطاطس تبين من الجدول رقم 7 أن متوسط نصيب البنة البطن الفرد في السنة من البطاطس بلغ نحو 28.51 كجم/سنة خلال الفترة (2000-2018) وذلك بحد أدنى بلغ نحو
} 


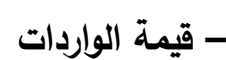
تبين من الجدول رقم 9 أن متوسط قيمة الواردات من محصول البطاطس بلغ نحو 76.47 ملئون 76.40 خلال النترة (2000-2018) وذلك بحد أدنى بلغ نحو

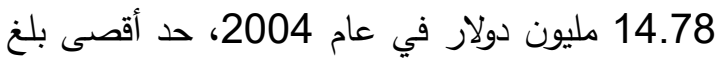
نحو 162.47 مليون دولار في عام 2016 2016، بزيادة قدرها

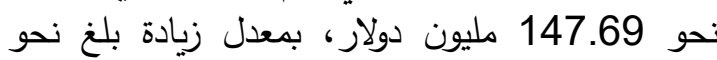

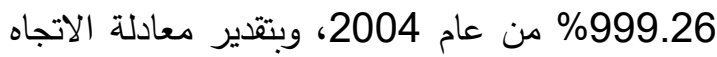

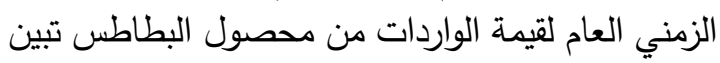

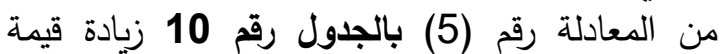
الواردات من محصول البطاطس بمقدار معنوي احصائيا

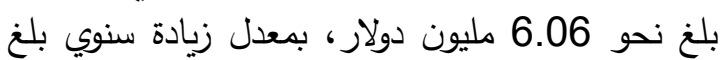

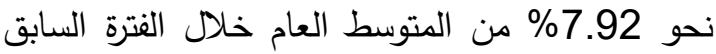
الاشارة اليها، وقد بلغ معامل التحديد نحو 0.60.

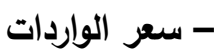
تبين من الجدول رقم 9 أن متوسط سعر الواردات من محصول البطاطس بلغ نحو 738.97 دولار خدار خلال

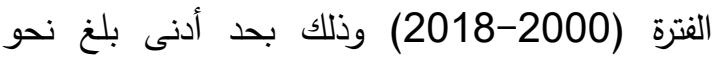
458.62 دولار في عام 2000 2000، حد أقصى بلغ نحو ندان

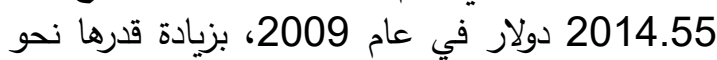

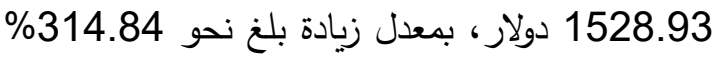

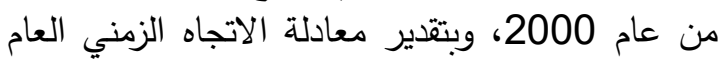

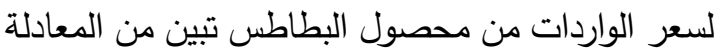

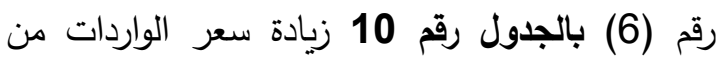
محصول البطاطس بمقدار غير معنوي احصائيا بلغ نحو رئر

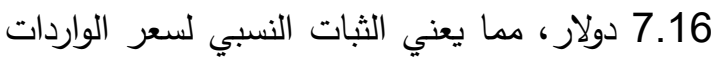

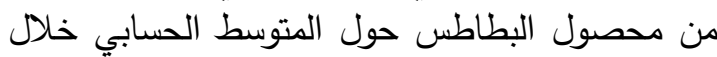

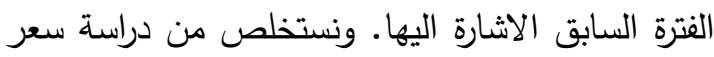

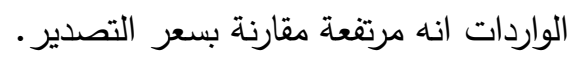

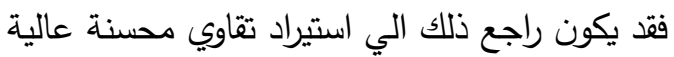

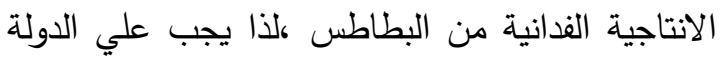

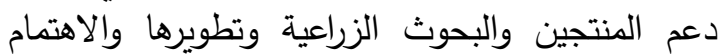
بانتاج تقاوي محسنة محلية عالية الانتاجية الفدانية والتي

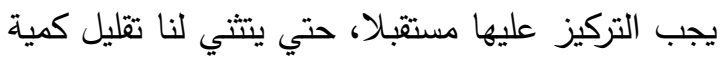

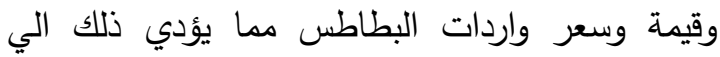
تحسين الميزان التجاري في مصر .
1093.1\% من عام 2000، وبتقدير معادلة الاتجاه الزمني العام لقيمة الصادرات من محصول البطاط تبين من المعادلة رقم (2) بالجدول رقم 10 زيادة قيمة

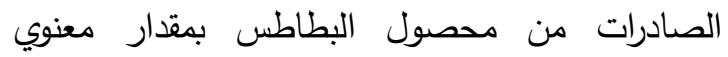

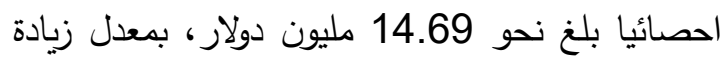

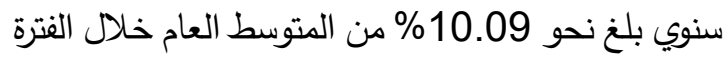
السابق الاشثارة اليها، وقد بلغ معامل التحديد نحو 0.79.

- السعر التصديري من الجدول رقم 9 أن متوسط السعر التصديري لمحصول البطاطس بلغ نحو 3018 نحون 338.37 دولار خلال

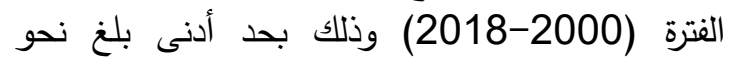
148.26 دولار في عام 2003- 2003، حد أقصى بلغ نحو

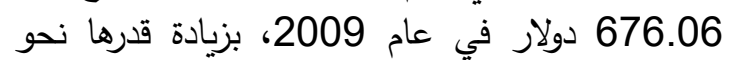

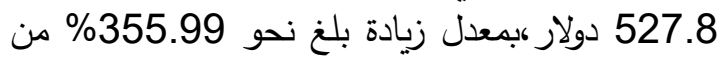
عام 2003، وبتقدير معادلة الاتجاه الزمني العام للسعر التصديري من محصول البطاطس تبين من المعادلة رقم (3) بالجدول رقم 10 زيادة السعر التصدير من من لئل محصول البطاطس بمقدار معنوي احصائيا بلغ نحو

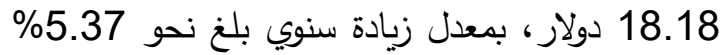
من المتوسط العام خلال الفترة السابق الآثارة اليها ، وقد بلغ معامل التحديد نحو 0.48. - كمية الواردات تبين من الجدول رقم 9 أن متوسط كمية الواردات

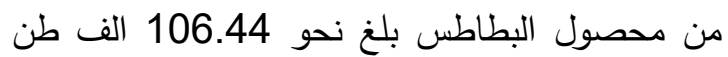
خلال الفترة (2000-2018) وذلك بحد أدنى بلى بلغ نحو 23.22 الف طن في عام 2004، حد أقدى أقى بلغ نحو

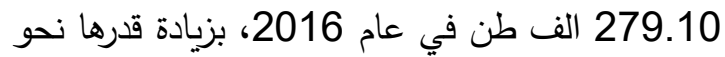

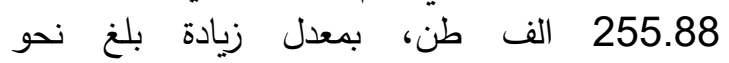
11.01.98\% من عام 2004، وبتقدير معادلة الاتجاه

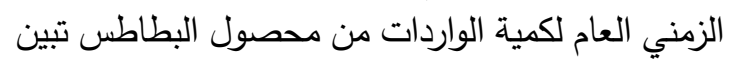
من الكعادلة رقم (4) بالجدول رقم 10 زيادة كمية الواردات من محصول البطاطس بمقدار معنوي احصائيا

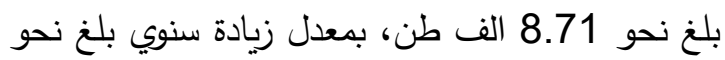
8.18 من المتوسط العام خلال الفترة السابق الاشارة اليها، وقد بلغ معامل التحديد نحو 0.181. 
جدول 9. تطور الانتاج الكلي وكمية وقيمة الصادرات وكمية وقيمة الواردات وسعر الصادرات والواردات وصافي الميزان التجاري من محصول البطاطس خلال الفترة وفية الهنادرات (2000-2018)

\begin{tabular}{|c|c|c|c|c|c|c|c|c|c|}
\hline $\begin{array}{c}\text { الصي الانتاج } \\
\text { الكمية }\end{array}$ & التجاريز & | الواردات & |لماردات & الف الفية & (التصديري & (مليون & (الصادرات & (الفلي طن & السنوات \\
\hline 8.87 & 5.03 & 485.62 & 32.42 & 66.76 & 174.87 & 27.39 & 156.63 & 1764.91 & 2000 \\
\hline 9.75 & 11.44 & 529.34 & 18.31 & 34.59 & 160.37 & 29.75 & 185.51 & 1903.13 & 2001 \\
\hline 11.55 & 12.53 & 542.55 & 30.09 & 55.46 & 185.79 & 42.62 & 229.38 & 1985.32 & 2002 \\
\hline 14.53 & 1.94 & 604.35 & 41.99 & 69.48 & 148.26 & 43.93 & 296.29 & 2039.35 & 2003 \\
\hline 14.98 & 52.45 & 636.52 & 14.78 & 23.22 & 176.22 & 67.23 & 381.51 & 2546.61 & 2004 \\
\hline 12.38 & 31.05 & 636.40 & 46.40 & 72.91 & 197.48 & 77.45 & 392.18 & 3167.43 & 2005 \\
\hline 15.87 & 35.63 & 512.33 & 29.72 & 58.01 & 178.00 & 65.35 & 367.13 & 2312.79 & 2006 \\
\hline 14.12 & 7.2 & 879.53 & 60.89 & 69.23 & 277.37 & 108.09 & 389.70 & 2760.46 & 2007 \\
\hline 11.16 & 108.85 & 824.05 & 67.30 & 81.67 & 442.65 & 176.15 & 397.94 & 3567.05 & 2008 \\
\hline 5.88 & 38.82 & 2014.55 & 106.59 & 52.91 & 676.06 & 145.41 & 215.08 & 3659.28 & 2009 \\
\hline 8.22 & 21.28 & 737.65 & 108.28 & 146.79 & 433.96 & 129.56 & 298.56 & 3634.22 & 2010 \\
\hline 14.69 & 124.17 & 880.53 & 126.48 & 143.64 & 393.23 & 250.65 & 637.43 & 4338.43 & 2011 \\
\hline 9.04 & 37.74 & 745.20 & 89.61 & 120.25 & 484.24 & 127.35 & 430.00 & 4758.04 & 2012 \\
\hline 10.55 & 59.23 & 795.05 & 146.67 & 184.48 & 481.17 & 205.90 & 450.00 & 4265.18 & 2013 \\
\hline 15.13 & 206.37 & 777.00 & 120.42 & 154.98 & 477.28 & 326.79 & 697.71 & 4611.07 & 2014 \\
\hline 12.13 & 157.85 & 690.10 & 78.05 & 113.10 & 387.52 & 235.90 & 600.99 & 4955.45 & 2015 \\
\hline 11.50 & 0.46 & 582.12 & 162.47 & 279.10 & 342.46 & 162.01 & 473.07 & 4113.44 & 2016 \\
\hline 13.87 & 187 & 561.24 & 85.73 & 152.75 & 406.28 & 272.73 & 671.29 & 4841.04 & 2017 \\
\hline 13.88 & 186 & 606.22 & 86.75 & 143.10 & 405.86 & 272.75 & 672.03 & 4842.03 & 2018 \\
\hline 12.00 & 7469. & 738.97 & 76.47 & 106.44 & 338.37 & 145.63 & 418.02 & 3477.12 & المتوسط \\
\hline
\end{tabular}

المصدر: 1 - وزارة الزراعة واستصلاح الاراضى، قطاع الثئون الاقتصادية، الإدارة المركزية للاقتصاد الزراعي، نشرة الاقتصاد الزراعي، أعداد مختلفة http//www.capmas.gov.org. موقع الجهاز المركزي للتعبئة العامة والاحصاء

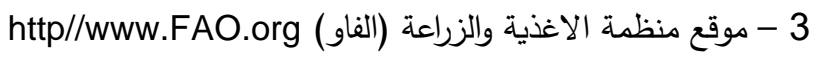


جدول 10. معادلات الاتجاة الزمني العام لتطور كمية وقيمة الصادرات وكمية وقيمة الواردات وسعر الصادرات والواردات وصافي الميزان التجاري من محصول البطاطس خلاد التاد الفترة (2000-2018)

\begin{tabular}{|c|c|c|c|c|c|c|}
\hline معل الزيادة او & المتوسط & $\mathbf{F}$ & $\mathbf{R}^{2}$ & المعادلات & البيان & b \\
\hline 6.07 & 418.02 & 38.72 & 0.70 & $\begin{array}{c}\hat{Y}=164.41+25.36 x \\
(3.55)^{* *}(6.24)^{* * *}\end{array}$ & كمية الصادرات & 1 \\
\hline 10.09 & 145.36 & 62.14 & 0.79 & $\begin{array}{l}\hat{Y}=-1.31+14.69 x \\
(-0.61)^{-}(7.88)^{* *}\end{array}$ & $\begin{array}{l}\text { قيمة الصادرات } \\
\text { (مليون دولار) }\end{array}$ & 2 \\
\hline 5.37 & 338.37 & 14.91 & 0.48 & $\begin{array}{c}\hat{Y}=156.61+18.18 x \\
(2.92)^{\star *}(3.86)^{\star *}\end{array}$ & 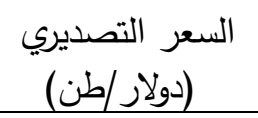 & 3 \\
\hline 8.18 & 106.44 & 26.54 & 0.61 & $\begin{array}{l}\hat{Y}=19.33+8.71 x \\
(1.01)^{-}(5.15)^{*}\end{array}$ & $\begin{array}{c}\text { كمية الواردات } \\
\text { (الف طن }\end{array}$ & 4 \\
\hline 7.92 & 76.47 & 25.36 & 0.60 & $\begin{array}{l}\hat{Y}=15.90+6.06 x \\
(1.16)^{-}(5.04)^{*}\end{array}$ & $\begin{array}{l}\text { قيمة الواردات } \\
\text { (مليون دولار ) }\end{array}$ & 5 \\
\hline- & 738.97 & 0.25 & 0.24 & $\begin{array}{c}\hat{Y}=667.34+7.16 x \\
(4.11)^{* *}(0.50)^{-}\end{array}$ & 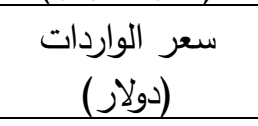 & 6 \\
\hline 12.17 & 69.74 & 15.43 & 0.49 & $\begin{array}{l}\hat{Y}=-15.16+8.49 x \\
(-0.62)^{-}(3.93)^{\star *}\end{array}$ & الميزان التجاري & 7 \\
\hline- & 12.00 & 0.26 & 0.22 & $\begin{array}{l}\hat{Y}=11.40+0.06 x \\
(8.46)^{\star *}(0.51)^{-}\end{array}$ & الي الانتاج الكلية الصادرات & 8 \\
\hline
\end{tabular}

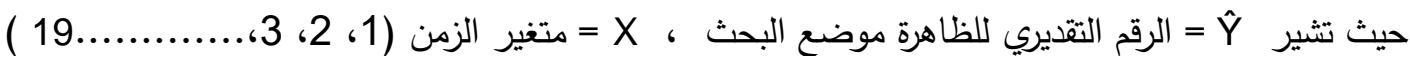

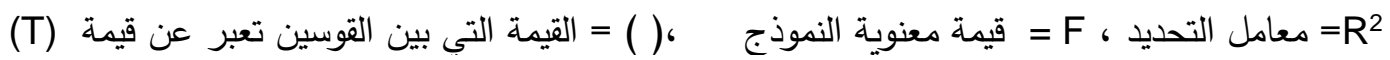

$$
\text { المصدر : جمعت وحسبت منوية } 0.01 \text { من الجداول رقم ( 9). }
$$

12.17\% من المتوسط العام خلال الفترة السابق الاشارة

اليها ، وقد بلغ معامل التحديد نحو

- نسبة كمية الصادرات الي الانتاج الكلي من محصول البطاطس

تبين من الجدول رقم 9 أن متوسط نسبة كمية الصادرات الي الانتاج من محصول البطاطس بلغ فلغ نحون

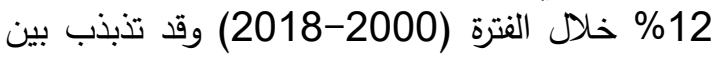
الزيادة والنقصان وقد تران

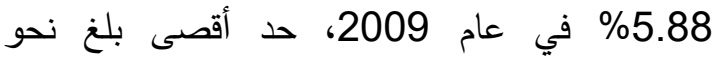
15.87\% في عام 2006، وبتقدير معادلة الاتجاه الزمني العام لنسبة كمية الصادرات الي الانتاج من
- صافي الميزان التجاري تبين من الجدول رقم 9 أن متوسط صافي الميزان

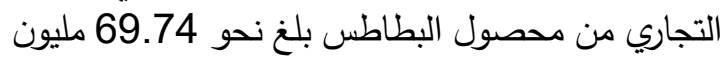
دولار خلال الفترة (2000-2018) وقد تذبذب الميزان التجاري لمحصول البطاطس بين الزيادة والنقصان وقد تراوح بين حد أدنى بلغ نحو 0.46 مليون دولار في ليط عام النيان

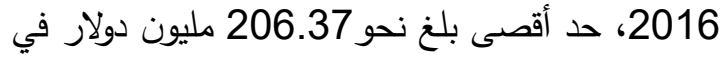
عام 2014، وبتقدير معادلة الاتجاه الزمني العام لصافي لئي الميزان التجاري لمحصول البطاطس تبين من المعادلة

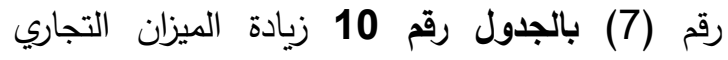

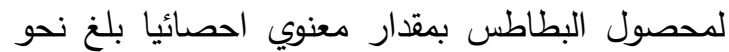
8.49 مليون دولار، بمعدل زيادة سنوي بلغ نحوب البطائ نحو 
$\mathrm{GR}=-\mathrm{NELP}-\mathrm{NELC}-\mathrm{PS}-\mathrm{CS}$

Change in Foreign Exchange

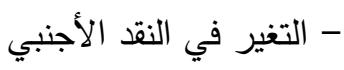

$F E=-P b(Q W-Q d+C d-C W)$

$$
\text { - صافى الأثر علي الصادرات أو الواردات }
$$

Net Effect on Export or Import

$\mathrm{NET}=\mathrm{PS}+\mathrm{CS}+\mathrm{GR}$

$$
\begin{aligned}
& \text { حيث : = حجم الإنتاج سعر الحدود . Q } \\
& \text { = حجم الإنتاج عند السعر المزرعى : Qd } \\
& \text { سعر الحدود Pb } \\
& \text { • Pd } \\
& \text { = حجم الاستهلاكى عند سعر الحدود = CW } \\
& \text { Cd } \\
& \text { PC }
\end{aligned}
$$

هذا وقد قدرت مرونة العرض الســـعرية من خلال

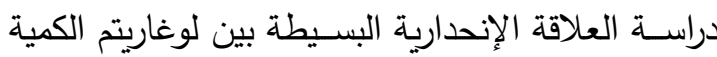

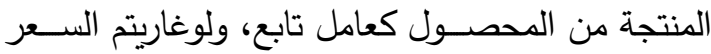

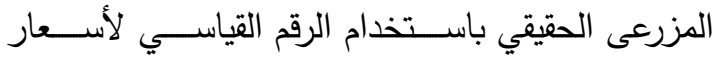

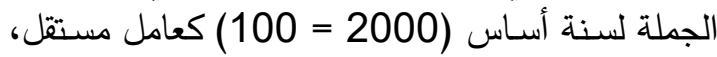

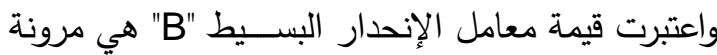

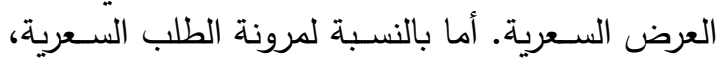

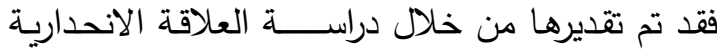

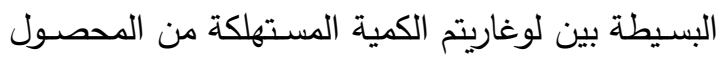

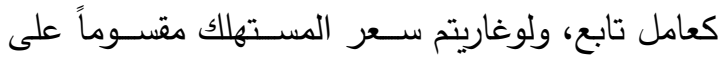

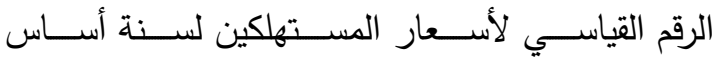
(2000= 100) كعامل مستقل، واعتبرت قيمة معامل الانحدار البسيط "B" هي مرونة الطلب السعرية ـ

\section{1- تقدير معامل ومعدل الحماية الاسمي}

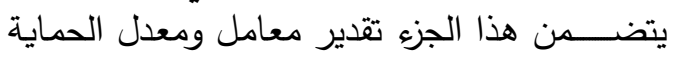

الاســـي وذلك بهدف التعرف علي التوجهات السـعرية

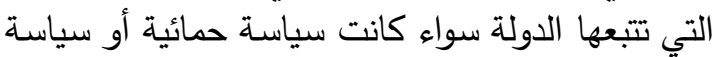
فرض ضرائب كما يلي:

- معامل الحماية الأسمى Nominal Protection -

Coefficient (NPC)

يعبر معامل الحماية الأســمى عن الانحراف أو الأ

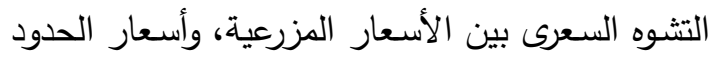

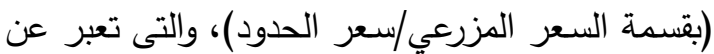

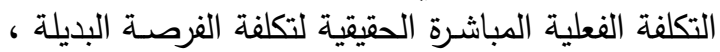

محصول البطاطس تبين من المعادلة رقم (8) بالجدول

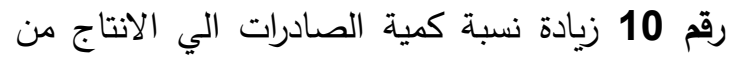
محصول البطاطس بمقدار غير معنوي احصائيا بلغ نحو

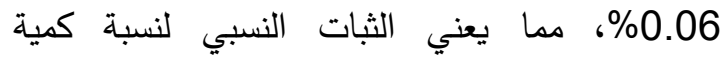

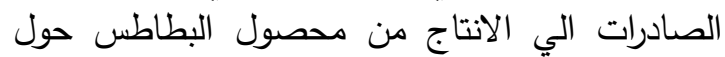
المتوسط الحسابي خلال الفترة السابق الاشارة اليها.

تانيا: تقدير معامل ومعدل الحماية الاسمي ونموذج التوازن الجزئي

يستخدم في قياس تأثير السياسات السعرية علي كل التي

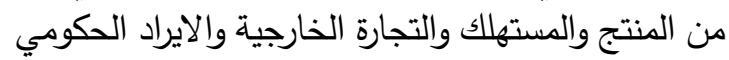

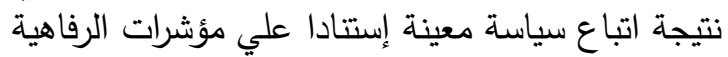
والكفاءة والايراد الحكومي. يوضــح نموذج التوازن الجزئي الاختلالات السـعرية

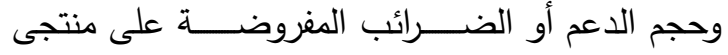

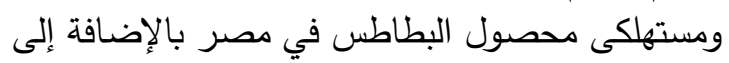

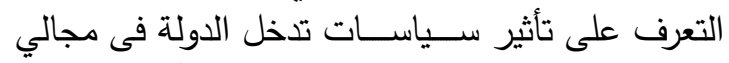

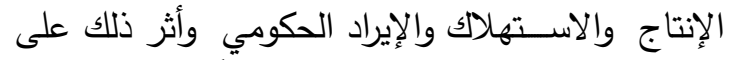

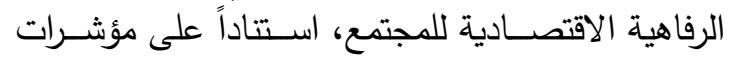

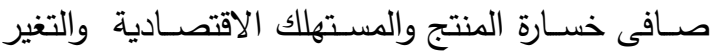

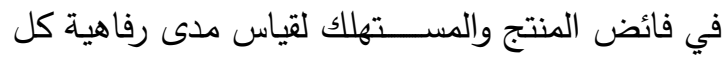

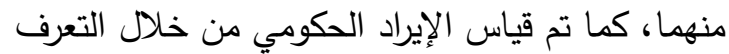

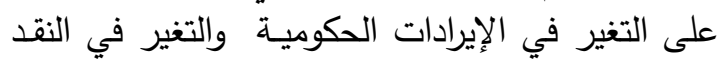

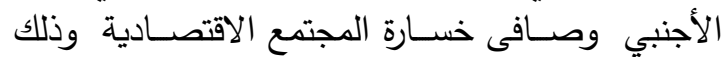

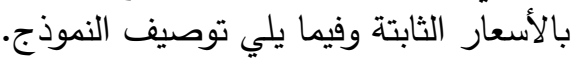
- صافى الخسارة الاقتصادية في الإنتاج Net Economic Loss in production.

$\mathrm{NELP}=(\mathrm{QW}-\mathrm{Qd}) *(\mathrm{~Pb}-\mathrm{Pd}) / 2$ - صافى الخسارة الاقتصادية في الاستهلاكs

Net Economic Loss in Consumption.

$\mathrm{NELC}=(\mathrm{CW}-\mathrm{Cd}) *(\mathrm{Pc}-\mathrm{Pb}) / 2$

Change in production Surplus.

$P S=Q d(P d-P b)-N E L P$

- التغير في فائض المستهلك

Change in Consumer Surplus

$\mathrm{CS}=\mathrm{Cd}(\mathrm{Pc}-\mathrm{Pd})-\mathrm{NELC}$
Change in Government Revenue

- التغير في الإيراد الحكومي

AUJASCI, Arab Univ. J. Agric. Sci., 29(1), 2021 


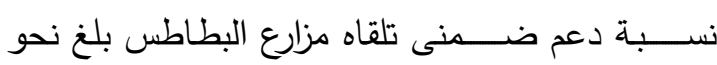

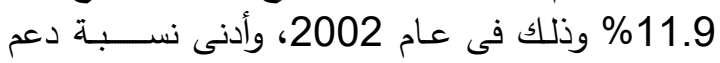
حوالى 10.4\% فى عام 2001.

Nominal Protection Coefficient (NPC)

وهو عبارة عن: معامل الحماية الاسمي (NPC-1)

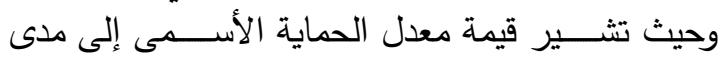

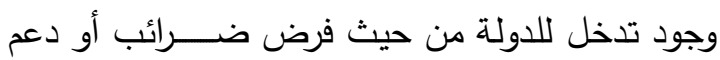

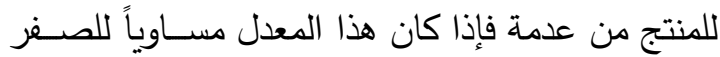

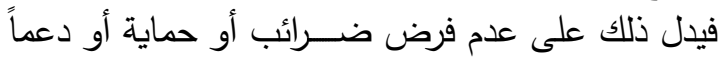

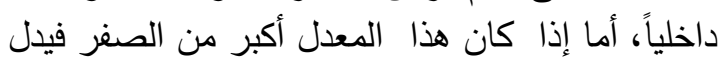

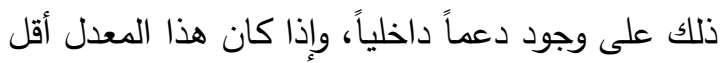

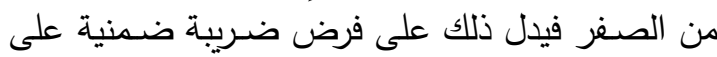

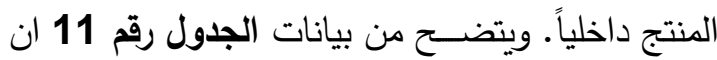

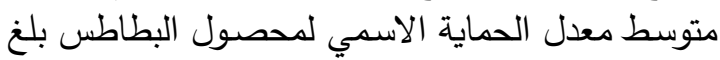

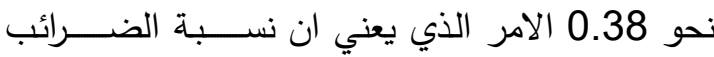

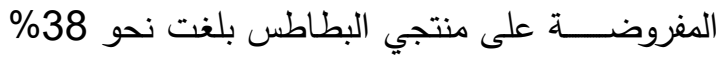
كما يتضح أيضًا أن قيم معامل الحماية الأسمى لأعوام

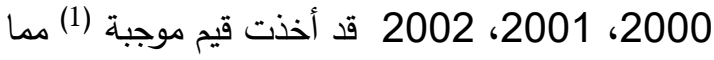

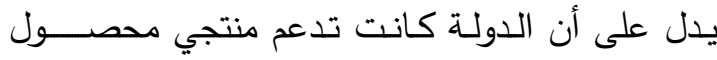

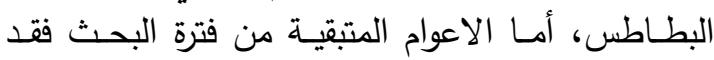

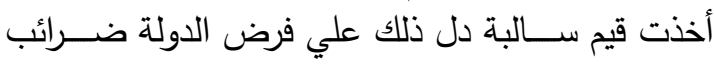

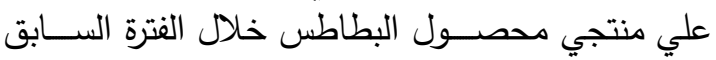

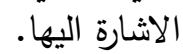

التي قد تتحملها أو تســـثيد منها الدولة وهناك ثلاث

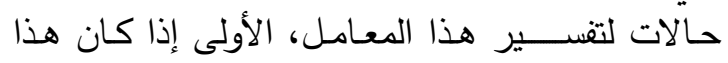

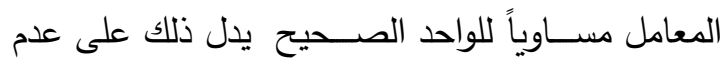

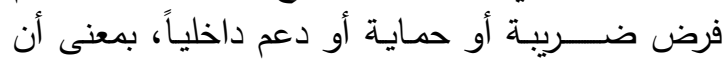

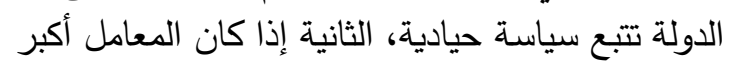

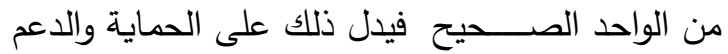

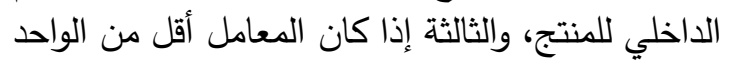

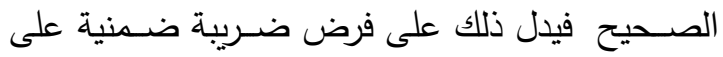
المنتج داخلياً.

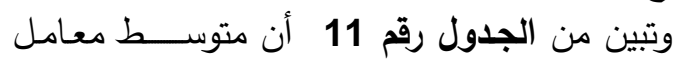

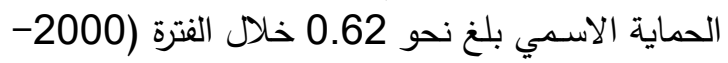

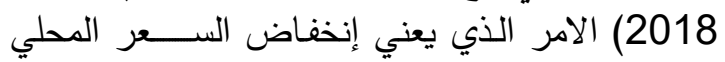

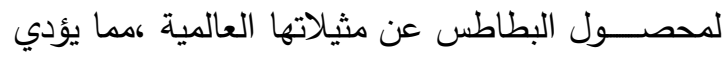

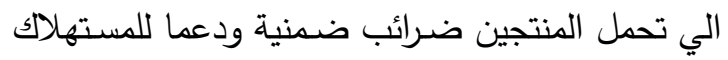

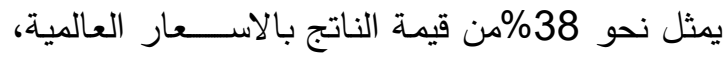

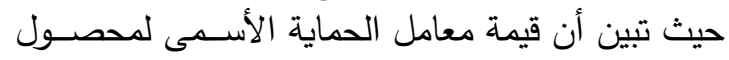

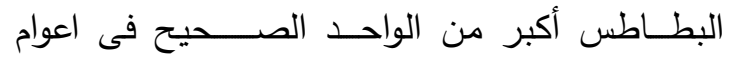

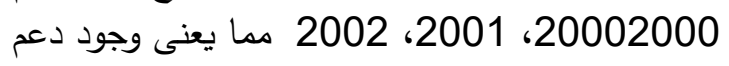

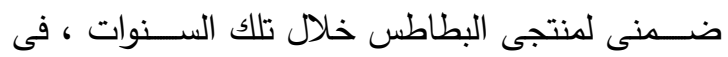

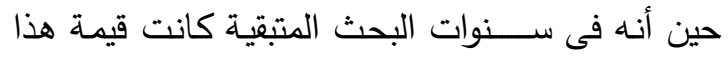
المعامل أقل من الواحد الصحيح مما يعنى تحمل المنتج

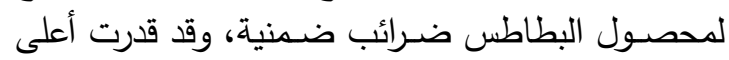

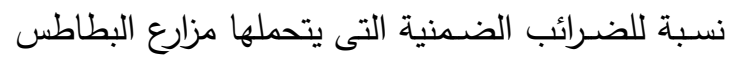

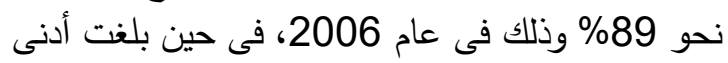
نسبة لها فى عام 2007 بنحو 23\% ونى فينما أعلى 
جدول 11. تطور معامل ومعدل الحماية الاسمى لمحصول البطاطس فى مصر خلال الفترة (2000-2018)

\begin{tabular}{|c|c|c|c|c|}
\hline $\begin{array}{c}\text { معدل الحماية الاسمي } \\
\text { (NPC-1) }\end{array}$ & معامل الحماية & سعر الحدود & $\begin{array}{c}\text { السعر المزرعي } \\
\text { الحقيقي } \\
\text { Pd }\end{array}$ & السنوات \\
\hline 0.07 & 1.07 & 0.148 & 0.159 & 2000 \\
\hline 0.04 & 1.04 & 0.156 & 0.162 & 2001 \\
\hline 0.19 & 1.19 & 0.138 & 0.164 & 2002 \\
\hline-0.19 & 0.81 & 0.191 & 0.154 & 2003 \\
\hline-0.23 & 0.77 & 0.240 & 0.184 & 2004 \\
\hline-0.62 & 0.38 & 0.503 & 0.192 & 2005 \\
\hline-0.69 & 0.31 & 0.546 & 0.169 & 2006 \\
\hline-0.77 & 0.23 & 0.576 & 0.131 & 2007 \\
\hline-0.73 & 0.27 & 0.572 & 0.155 & 2008 \\
\hline-0.69 & 0.31 & 0.521 & 0.159 & 2009 \\
\hline-0.68 & 0.32 & 0.550 & 0.174 & 2010 \\
\hline-0.73 & 0.27 & 0.558 & 0.152 & 2011 \\
\hline-0.43 & 0.57 & 0.420 & 0.239 & 2012 \\
\hline-0.24 & 0.76 & 0.342 & 0.260 & 2013 \\
\hline-0.41 & 0.59 & 0.477 & 0.283 & 2014 \\
\hline-0.20 & 0.80 & 0.387 & 0.309 & 2015 \\
\hline-0.11 & 0.89 & 0.342 & 0.303 & 2016 \\
\hline-0.48 & 0.52 & 0.422 & 0.218 & 2017 \\
\hline-0.31 & 0.69 & 0.352 & 0.244 & 2018 \\
\hline 830. & 260. & 0.39 & 0.201 & المتوسط \\
\hline
\end{tabular}

المصدر: 1 - وزارة الزراعة واستصلاح الاراضى، قطاع الشئون الاقتصادية، الإدارة المركزية للاقتصاد الزراعي، نشرة الاقتصاد الزراعي، أعداد مختلفة الزراعة

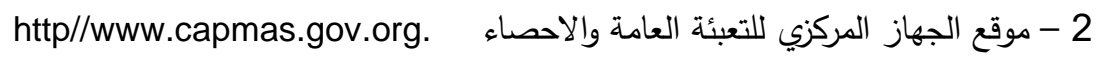

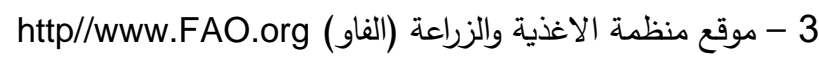

$$
\text { 1- 1 }
$$

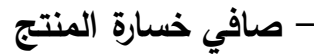
بإستعراض البيانات الواردة بالجدول رقم 12 تبين أن

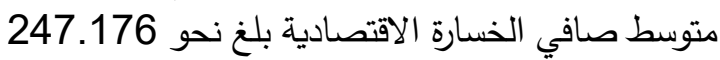
الف جنيه خلال الفترة (2000-2018) وذلك بحد بحد أدني بلغ نحو 0.169 الف جنيه في عام 2001، وحد أقصي
2- تقدير نموذج التوازن الجزئي

\section{Partial Equilibrium Model ( PEM)}

يتاول هذا الجزء تقدير اثر السياسة السعرية والتي تمثلت

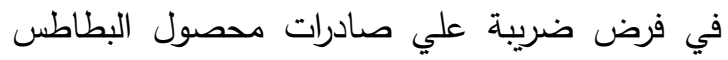
بإستخدام نموذج التوازن الجزئي علي كفاءة استخدام المدخلات والمخرجات والرفاهية الاقتصادية علي مستوي المجتمع والايراد الحكومي كما يلي: 
العالمي وزيادة التكاليف الانتاجية ،مما يؤدي الي ترشيد

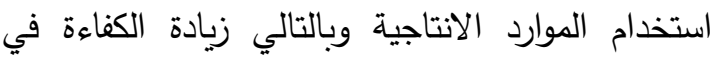

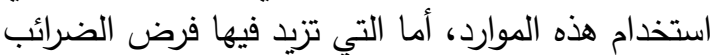

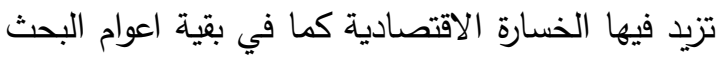

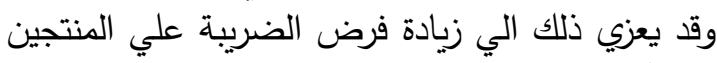
مما أدي الي انخفاض الاسعار المحلية عن الاسعار الطنين

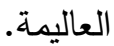

بلغ نحو 1881.920 الف جنيه في عام 2011، بزيادة

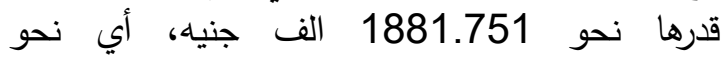
1113462\% من عام 2001، وقد تبين ان الاعوام التي تقل فيها فرض الضريبة أي يكون هناك دعما تقل فئ الاعل

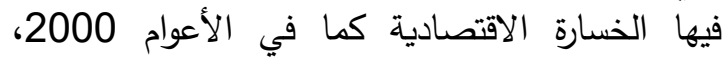

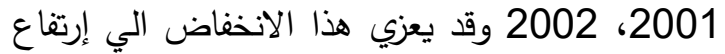
الاسعار المحلية لمحصول البطاطس واقترابها من السعر السترع

جدول 12. نتائج تقدير نموذج التوازن الجزئي لدحصول البطاطس في مصر خلال الفترة (2000-2018)

\begin{tabular}{|c|c|c|c|c|c|c|c|}
\hline صافي الاثر & النقد الأجنبي & الايلغير في & $\begin{array}{c}\text { التغير في } \\
\text { فائضلاك } \\
\text { ( SC) }\end{array}$ & التغير في & الاقتصادية في الاخسارة & | الاقتصادية في الخسارة & للسنوات \\
\hline 3.802 & 53.372 & 19.856 & -34.931 & 18.877 & -4.339 & 0.537 & 2000 \\
\hline 2.298 & 39.583 & 22.156 & -31.108 & 11.250 & -2.467 & 0.169 & 2001 \\
\hline-3.258 & 32.683 & -54.340 & 2.737 & 48.3 & -0.015 & 3.273 & 2002 \\
\hline 18.815 & 56.150 & 177.904 & $-76.3 \varepsilon$ & -82.7 & -26.066 & 7.252 & 2003 \\
\hline 62.862 & 161.731 & 337.538 & -114.7 & -159. & -80 & 17.361 & 2004 \\
\hline-30.544 & -302.741 & 1694.686 & -101.916 & -1623.314 & -607.699 & 638.244 & 2005 \\
\hline 141.195 & 64.630 & 1495.009 & 296.131 & -1649.944 & -919.218 & 778.022 & 2006 \\
\hline-27.357 & -388.921 & 2070.636 & 799.542 & -2897.535 & -1641.773 & 1669.130 & 2007 \\
\hline 705.437 & 1093.498 & 2620.696 & 1172 & -3088. & -230 & 1600.698 & 2008 \\
\hline 1147.532 & 2089.356 & 2433.774 & 1244. & -2531 & -235 & 1206.356 & 2009 \\
\hline 1791.148 & 3370.257 & 2510.798 & 1827.948 & -2547.597 & -2972.279 & 1181.131 & 2010 \\
\hline 889.513 & 1204.192 & 2844.893 & 1687.943 & -3643.322 & -2771.433 & 1881.920 & 2011 \\
\hline 1088.134 & 2141.857 & 1711.275 & 498.949 & -1122.0 & -134 & 260.884 & 2012 \\
\hline 727.782 & 1694.391 & 1023.281 & \begin{tabular}{|l|}
98.368 \\
\end{tabular} & -393.8 & -771.904 & 44.122 & 2013 \\
\hline 1131.329 & 2441.820 & 2056.628 & 214.538 & -1139.837 & -1376.618 & 245.290 & 2014 \\
\hline 606.627 & 1542.210 & 1215.325 & -183.145 & -425.553 & -645.655 & 39.028 & 2015 \\
\hline 783.981 & 2085.153 & 998.774 & -46.1 & -168. & & 8.2 & 2016 \\
\hline 976.466 & 2032.158 & 2116.513 & 217.1 & -1357 & & 369.660 & 2017 \\
\hline 704.009 & 1666.935 & 1402.506 & -82.9 & -615. & & 92.586 & 2018 \\
\hline 426.096 & 829.035 & 1309.882 & 20.566 & -904.352 & -673.272 & 247.176 & الكتوسط \\
\hline
\end{tabular}

المصدر : جمعت وحسبت من الجدول رقم (1) بالملحق 


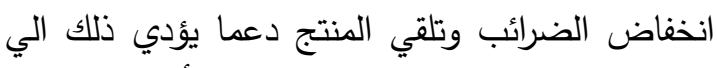

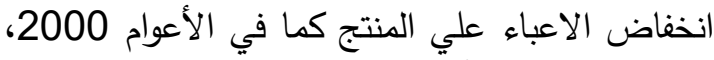

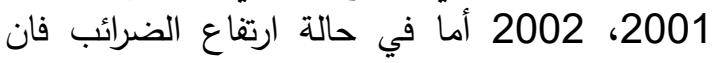
المنتج يتحمل عبء اكبر كما في بقية اعوام البحث الفرائ فان

$$
\text { - التغير في فائض المستهلك: }
$$

تبين من الجدول رقم 12 أن الن متوسط فائض المستهلك بلغ نحو 200066 الجئ 2018 الف جنيه خلال الفترة (2018-2000) ويلاحظ وجود تذبذب بئ بين الزيادة والنقصان في فائض المستهلك، وذلك بحد أدني بلغ نحو

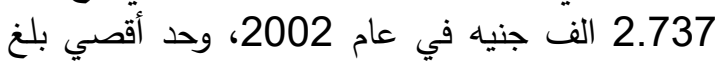
نحو 1827.948 الف جنيه في عام 2010، وقدات وقد ترجع

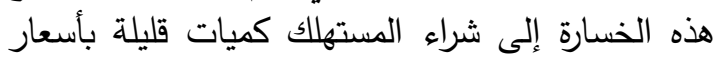

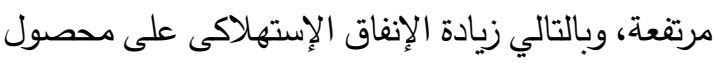

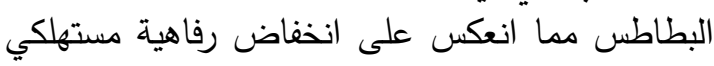

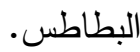

\section{3- مؤشرات عوائد الحكومة}

- - التغير في الايراد الحكومي: تبين من الجدول رقم 12 أن متوسط الايراد التيراد الحكومي

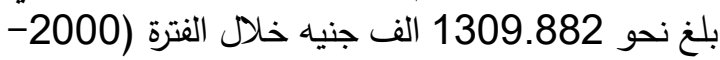
2018) وذلك بحد أدني بلغ نحو 19.856 الف جنيه

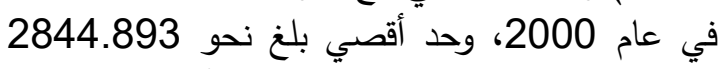

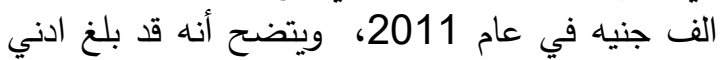
عائد في الايراد الحكومي في الأعوام 2002 2000، 2001، 2002 وذلك قد يكون راجع الي انخفاض الضيك الضريبة

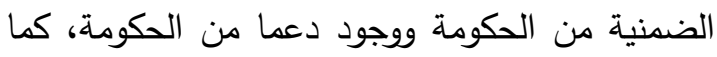
يتضح ان أعلي عائد في الايراد الحكومي في بقية الحئ الاعوام وقد يكون راجع الي ارتفاع الضريبة الضمنية الئي المفروضة الضية

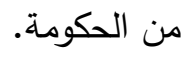

- التغير في النقد الاجنبي تبين من الجدول رقم 12 أن متوسط التغير في النقد الاجنبي بلغ نحو 829.035 الف جنيه خلاد الفي الفترة (2000-2018) وذلك بحد أدني بلغ نحو 32.683 الف جنيه في عام 2002، وحد أقصي بلغ نحو نحو 3370.257 الف جنيه في عام 2010، ويتضح أنه
-

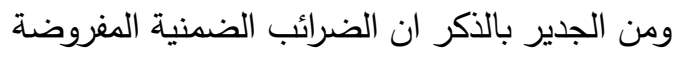

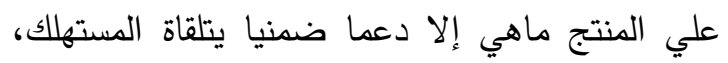
وباستعراض البيانات الواردة بالجدول رقم 12 تبين أن دأن متوسط صافي خسارة المستهلك بلغ نحو 673.272 الف جنيه خلالّ الفترة (2000-018

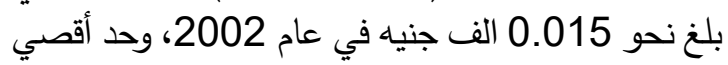

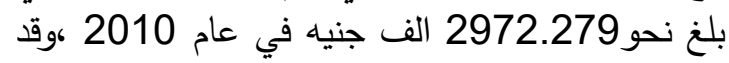
تبين ان الاعوام التي تقل فيها خسارة المستهلك كما في في

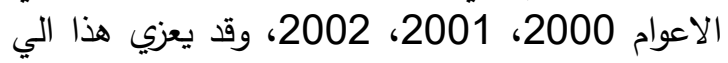

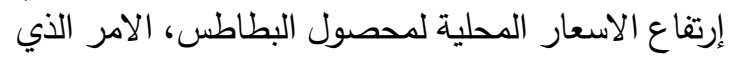

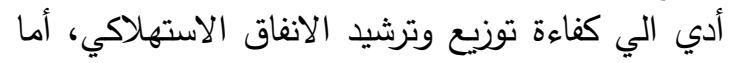

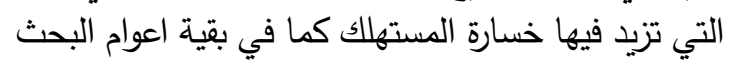

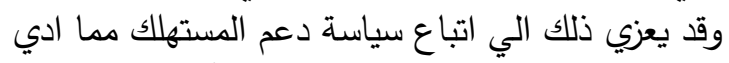

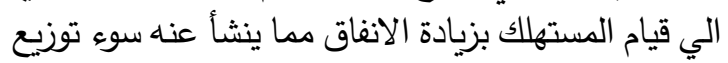

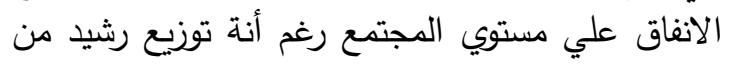
وجهة نظر المستهلك.

- صافي الاثر الاقتصادي (صافي الخسارة الاقتصادية)

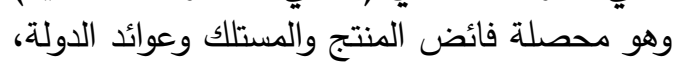
حيث تبين من الجدول رقم 12 ان متوسط صافي الائر المن وعائ الاقتصادي علي المجتمع والدولة بلغ نحو 426.096 ندان الف جنيه خلال الفترة (2000-2018) وقد تراوح بين

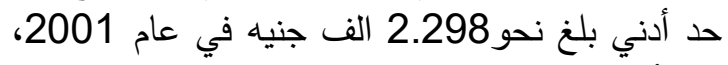

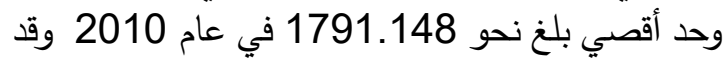
تذبذب بين الزيادة والنقصان خلاد الفترة السابق الاشارة

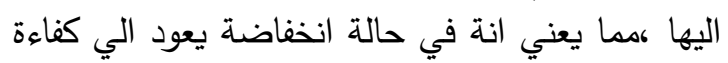

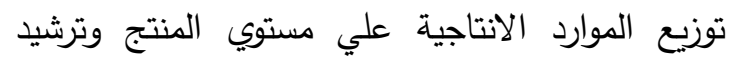
الانفاق الاستهلاكي علي مستوي المستهلك والعكس.

2- - يؤشرات الرفاهية

- التغير في فائض المنتج تبين من الجدول رقم 12 أن متوسط فائض المنتج بلغ نحو 904.352 الف جنيه خلال الفترة (2018 (2000 2018) وذلك بحد أدني بلغ نحو 11.250 الف جنيه في عام 2001، وحد أقصي بلغ نحو 3643.322 الف جنيه في عام 2011، ويتضح أنه في حالة 
4 -التوسع في انتاج البطاطس لضمان زيادة الكمية الزصدرة منها وبالتالي زيادة قيمة الصادياد زبادارت الزراعية وعائد الحكومة من النقد الاجنبي. 5 - توفير قاعدة البيانات اللازمة للمنتجين فيما يتعلق الأني بالكيات المرغوبة والاسعار والترتيبات التعاقدية بين الزراع والمصدرين.

\section{المراجـح}

حمدي عبدة الصوالجي (2009) الطلب علي البطاطس

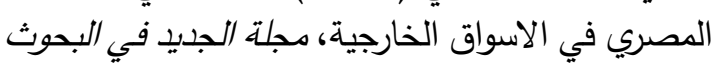

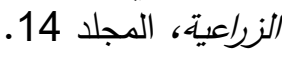

حسن عبد الغفور العباسي (2008) تحليل السياسات الزراعية للقطن المصري، الدجلة المصرية للاقتصاد الهيل الزراعي، المجلد 18.

حسين حسن على آدم (2004) اقتصاديات إنتاج

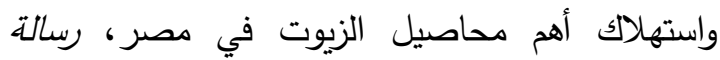
دكتورة، قسم الاقتصاد الزراعي كلية الززراعة ـ جامعة المعالة

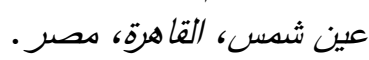
عمر مصطفي عبدالله (2015) دراسة إقتصادية لانتاج واستهلاك البطاطس فى مصر، مجلة اسيوط للعلوم الزراعية، المجلد

محمد عبد العزيز سيد خليل (2013) أثر السياسات السعرية الزراعية على محصول الذرة الثامية في مصر ، الثرات الثيات مجلة العلوم الزراعية والاقتصادية، المجلد 12.

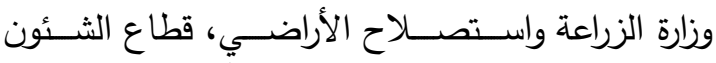
الاقتصادية، نشرة الاقتصاد الزراعي، أعداد مختلفة الاراض

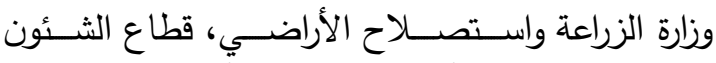
الاقتصادية، نشرة الأسعار المزرعية، أعداد مختلفة الألة

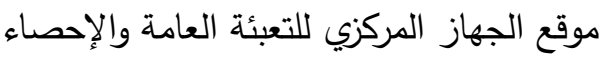
http://www.capmas.gov.eg موقع مركز المعلومات ودعم اتخاذ القرار http://www.idsc.gov.eg

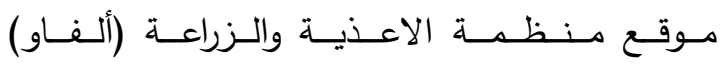
http://www.FAO.org
في حالة انخفاض الضرائب فانة يقل العجز في النقد الأدام

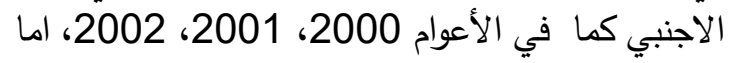
في حالة زيادة فرض الضرام الضريبة كلما زاد العجز في النقد

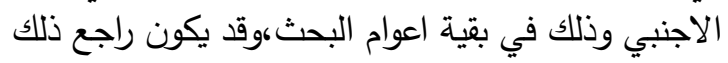

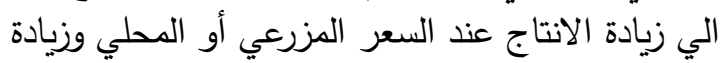

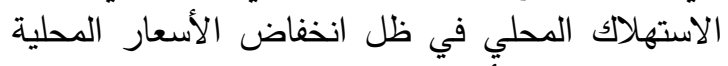

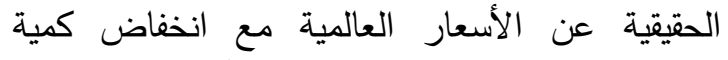

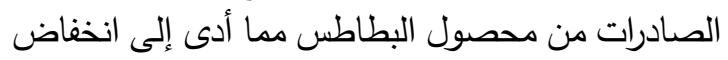
قيمة الصادرات خلال الفترة السابق الاشارة اليها. ونستخلص مما سبق أن المستهلك هو الإنارت المستفيد الوحيد الذي حقق مكاسب من السياسة السعرية لمحصول

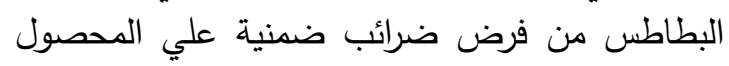

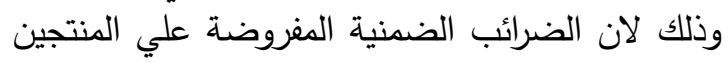

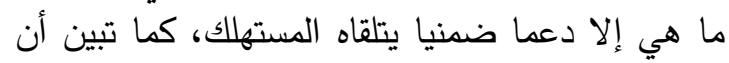

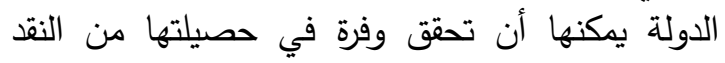
الاجنبي اذا ما تم تطبيق السياسة السعرية التي بمقتضاها أن يحصل المنتج علي العائد الحقيقي لإنتاجة وتحميل بلتيل

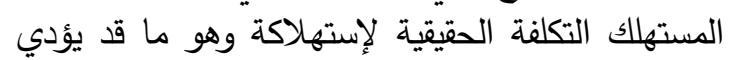
الي ترشيد الاستهلالك ومن ثم زيادة حجم صادرات مصر لإن

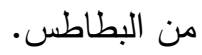
6

ومن خلال النتائج السابق يوصي البحث بما يلي

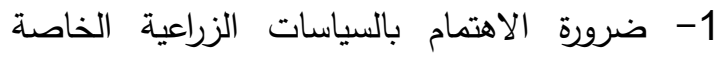
بتخفيف الضرائب المباشرة والغير مباشرة المغروضة التئة

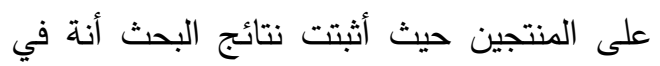

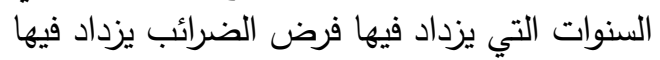
صافى الخسارة الاقتصادية في الإنتاج والعكس في في

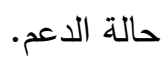

2- الاهتمام بالطلب الخارجى للبطاطس ودراسة الذوق اللمستهلك الخارجى ودراسة الدول المنافسة من حيث النائ

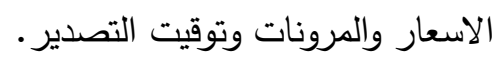
3- ضرورة الاهتمام بالسياسات الزراعية الخاصة بدعم الاتئ

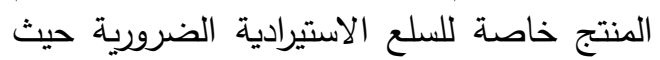
أثبتت نتائج البحث أنه بتقديم الدعم للمنتج تقل

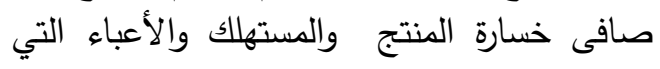
يتحملها المنتج ايضًا كما يكون هناك تغير في النقد الأجنبي في صالح الدولة. 


\section{الملحق}

جدول 1. تطور بعض المتغيرات الإنتاجية والاقتصادية لمحصول البطاطس فى مصر خلال الفترة (2000-2018)

\begin{tabular}{|c|c|c|c|c|c|c|c|c|c|c|}
\hline $\begin{array}{c}\text { الحدود_اكلاك } \\
\text { CW }\end{array}$ & $\begin{array}{c}\text { الحدودانتاج } \\
\text { Qw }\end{array}$ & مرونة & | مرونة & \begin{tabular}{|c} 
الف جنيه \\
الحدود \\
Pb
\end{tabular} & الف جنيه المزرعي & الحقيقي الفتل & 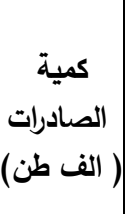 & (الاستهلاك & (الإنتاج الكلى طن) & سنوات \\
\hline 1452.94 & 1667.23 & 0.77 & 0.80 & 0.148 & 0.159 & 0.115 & 156.63 & 1190 & 1764.91 & 2000 \\
\hline 1540.35 & 1846.74 & 0.77 & 0.80 & 0.156 & 0.162 & 0.131 & 185.51 & 1343 & 1903.13 & 2001 \\
\hline 1346.03 & 1733.52 & 0.77 & 0.80 & 0.138 & 164 & 0.140 & 229.38 & 1361 & 1985.32 & 2002 \\
\hline 2033.96 & 2431.33 & 0.77 & 0.80 & 0.191 & 0.154 & 0.115 & 296.29 & 1348 & 2039.35 & 2003 \\
\hline 2865.92 & 3166.65 & 0.77 & 0.80 & 0.240 & 0.184 & 0.116 & 381.51 & 1572 & 2546.61 & 2004 \\
\hline 5547.59 & 7271.89 & 0.77 & 0.80 & 0.503 & 0.192 & 0.156 & 392.18 & 2045 & 3167.43 & 2005 \\
\hline 5684.81 & 6440.23 & 0.77 & 0.80 & 0.546 & 0.169 & 0.113 & 367.13 & 1439 & 2312.79 & 2006 \\
\hline 8577.50 & 10262.17 & 0.77 & 0.80 & 0.576 & 0.131 & 0.095 & 389.70 & 1751 & 2760.46 & 2007 \\
\hline 11944.92 & 11244.26 & 0.77 & 0.80 & 0.572 & 0.155 & 0.091 & 397.94 & 2356 & 3567.05 & 2008 \\
\hline 13190.23 & 10324.23 & 0.77 & 0.80 & 0.521 & 0.159 & 0.080 & 215.08 & 2515 & 3659.28 & 2009 \\
\hline 14799.35 & 9916.83 & 0.77 & 0.80 & 0.550 & 0.174 & 0.071 & 298.56 & 2389 & 3634.22 & 2010 \\
\hline 13662.59 & 13608.97 & 0.77 & 0.80 & 0.558 & 0.152 & 0.073 & 637.43 & 2234 & 4338.43 & 2011 \\
\hline 10497.36 & 7640.74 & 0.77 & 0.80 & 0.420 & 0.239 & 0.082 & 430.00 & 2515 & 4758.04 & 2012 \\
\hline 8661.50 & 5341.32 & 0.77 & 0.80 & 0.342 & 0.260 & 0.086 & 450.00 & 2631 & 4265.18 & 2013 \\
\hline 10875.88 & 7139.83 & 0.77 & 0.80 & 0.477 & 0.283 & 0.117 & 697.71 & 3228 & 4611.07 & 2014 \\
\hline 8185.75 & 5956.16 & 0.77 & 0.80 & 0.387 & 0.309 & 0.128 & 600.99 & 3200 & 4955.45 & 2015 \\
\hline 9970.50 & 4537.00 & 0.77 & 0.80 & 0.342 & 0.303 & 0.099 & 473.07 & 3450 & 4113.44 & 2016 \\
\hline 11978.66 & 8465.16 & 0.77 & 0.80 & 0.422 & 0.218 & 0.103 & 671.29 & 3539 & 4841.04 & 2017 \\
\hline 10011.16 & 6556.58 & 0.77 & 0.80 & 0.352 & 0.244 & 0.105 & 672.03 & 3561 & 4842.03 & 2018 \\
\hline 7039.61 & 6092.74 & 0.77 & 0.8 & 0.39 & 0.201 & 0.106 & 418.02 & 2298.26 & 3477.12 & المتوسط \\
\hline
\end{tabular}

المصدر: 1 - وزارة الزراعة واستصلاح الاراضى، قطاع الثئون الاقتصادية، الإدارة المركزية للاقتصاد الزراعي، نشرة الاقتصاد الزراعي،

أعداد مختلفة

http//www.capmas.gov.org. - موقع الجهاز المركزي للتعبئة العامة والاحصاء

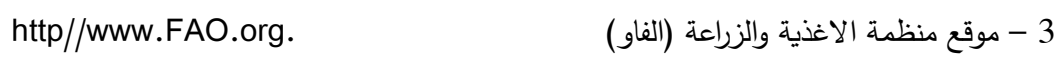

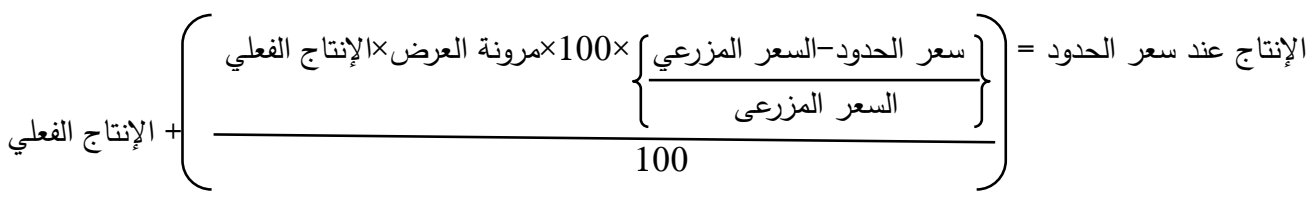

الإستهلاك عند سعر الحدود $\}$

AUJASCI, Arab Univ. J. Agric. Sci., 29(1), 2021 
حسين آدم 


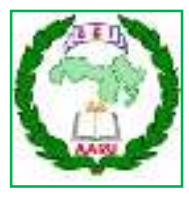

Arab Univ. J. Agric. Sci., Ain Shams Univ., Cairo, Egypt

29(1), 59 - 82, 2020

Website: http://ajs.journals.ekb.eg

DOI: 10.21608/ajs.2020.40679.1244

\title{
The Effect of Price Policies on the Most Important Economic Variables for the Potato Crop in Egypt
}

\author{
Hussein HA Adam* \\ Agricultural Economics Dept, Fac of Agric and Natural Resources, Aswan Univ, \\ Aswan, Egypt \\ *Corresponding author: hhussienadam@yahoo.com
}

Received 26 August, 2020

Accepted 21 February, 2021

\section{Abstract}

Potato occupies a distinguished position in the Egyptian agricultural economy, whether in terms of its contribution to agricultural income or in terms of cultivated area, in addition to being one of the important food crops in the Egyptian dietary pattern in addition to being one of the most important Egyptian agricultural exports. The research aims to measure the effect of price policies on the most important economic variables of the potato crop by identifying both the productive and economic indicators of the potato crop in Egypt. The extent of deviation of the price that producers get from the real price that they must obtain. The efficiency of using agricultural resources for the potato crop. The effect of the price policy of potato crop on the product's well-being and consumer and government revenues. It was found from the results of the research that the average area cultivated with the potato crop amounted to about 317.74 thousand feddans. The feddan productivity the total production amounted to about 10.82 tons, 3477.12 thousand tons, respectively, and that the average total costs. Total income, net revenue per feddan, and farm price reached about 955453 , 13704.05 , 4149.58, and 1147.68 pounds respectively, and the ratio of total revenue to total costs. The profitability of the produced ton, and the profit of the invested pound amounted to about $1.53,0.53$ and 381.87 pounds, respectively, during the period (2000-2018), as it turned out that. The value of production inputs,
\end{abstract}

the added value amounted to about 8097.89, 5606.16 pounds, and the average consumption. The amount of waste, and the surplus of the potato crop in Egypt amounted to about $2,297.89,425.32$ and 1179.22 thousand tons, respectively, and the rate of self-sufficiency of the potato crop in Egypt reached About $152.99 \%$, the average per capita consumption of the potato crop in Egypt was about $28.51 \mathrm{~kg}$ / year, and the average quantity and value of exports and imports of potatoes amounted to about 418.02, 106.44 thousand tons, 145.63 and 76.47 million dollars per ton respectively, and the trade balance of potatoes reached about 7469 million Dollars during the period Previous reference to it. The nominal protection coefficient and rate and the partial equilibrium model were also estimated in order to study the effect of price policies on both the producer. The consumer, foreign trade and government revenue as a result of following a certain policy based on the indicators of welfare, efficiency and government revenue. About 0.62, 0.38 , respectively, during the period (20002018), as it was found that the average net economic loss. The net economic impact on society and the state, producer surplus, government revenue, and the change in foreign exchange amounted to about 247.176, 426.96, 904.352, 1309.882, 829.035 thousand pounds, respectively, during the period (2000-2018).

Keywords: Price policy; Egyptian agricultural exports; potato; Partial equilibrium model 

Arab Univ. J. Agric. Sci., Ain Shams Univ., Cairo, Egypt 29(1), 59 - 82, 2020

Website: http://ajs.journals.ekb.eg 